NBER WORKING PAPER SERIES

PRICE SETTING IN A LEADING SWISS ONLINE SUPERMARKET

Martin Berka

Michael B. Devereux

Thomas Rudolph

Working Paper 17126

http://www.nber.org/papers/w17126

\author{
NATIONAL BUREAU OF ECONOMIC RESEARCH \\ 1050 Massachusetts Avenue \\ Cambridge, MA 02138 \\ June 2011
}

Devereux thanks SSHRC, the Royal Bank, and the Bank of Canada for financial support. The views in this paper are those of the authors alone and do not represent the views of the Bank of Canada or the National Bureau of Economic Research.

(C) 2011 by Martin Berka, Michael B. Devereux, and Thomas Rudolph. All rights reserved. Short sections of text, not to exceed two paragraphs, may be quoted without explicit permission provided that full credit, including (C) notice, is given to the source. 
Price Setting in a Leading Swiss Online Supermarket

Martin Berka, Michael B. Devereux, and Thomas Rudolph

NBER Working Paper No. 17126

June 2011

JEL No. E3

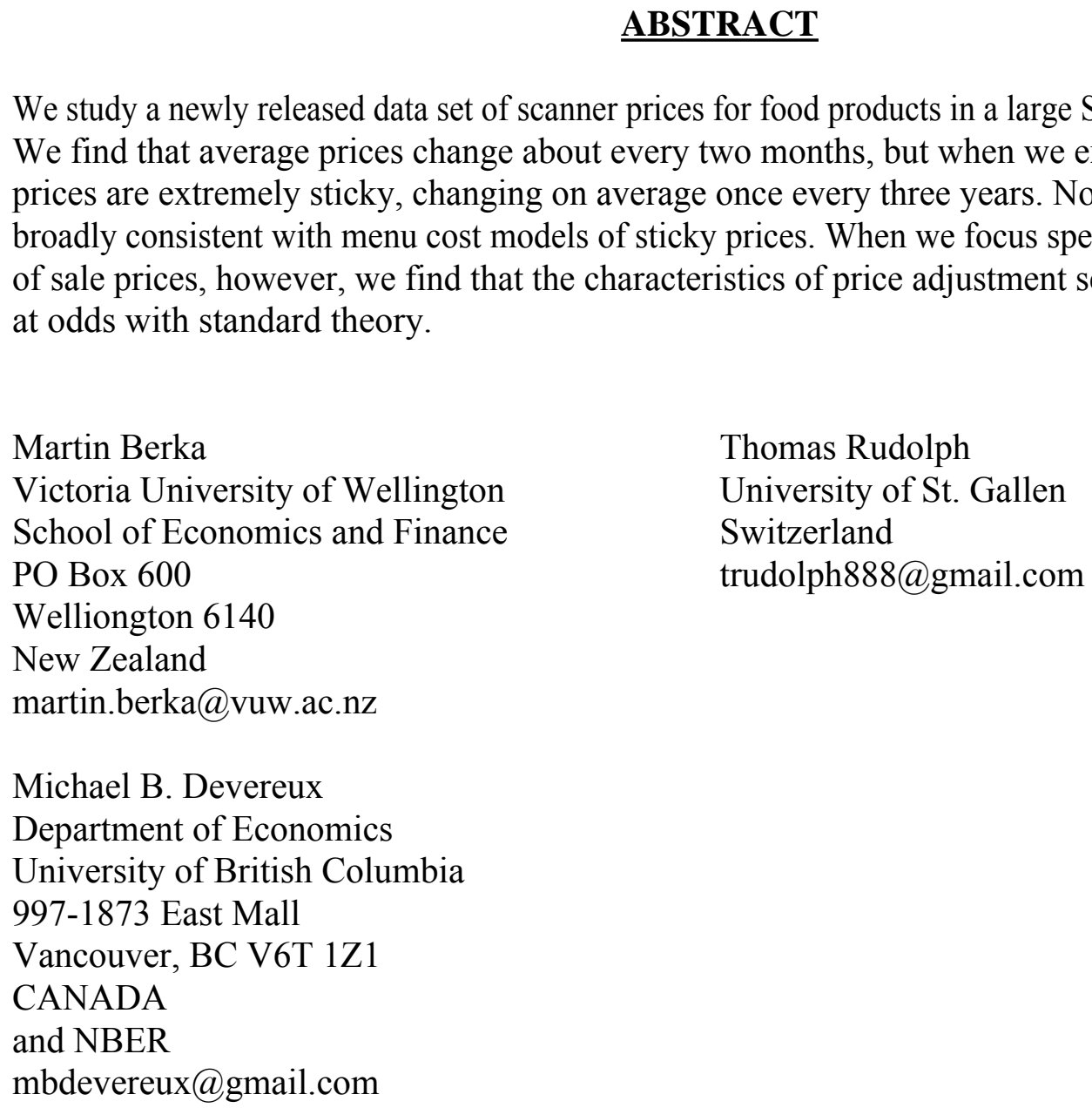

ABSTRACT at odds with standard theory.

Martin Berka

Victoria University of Wellington

School of Economics and Finance

PO Box 600

Welliongton 6140

New Zealand

martin.berka@vuw.ac.nz

Michael B. Devereux

Department of Economics

University of British Columbia

997-1873 East Mall

Vancouver, BC V6T 1 Z1

CANADA

and NBER

mbdevereux@gmail.com

Thomas Rudolph

University of St. Gallen

Switzerland

trudolph888@gmail.com

We study a newly released data set of scanner prices for food products in a large Swiss online supermarket. We find that average prices change about every two months, but when we exclude temporary sales, prices are extremely sticky, changing on average once every three years. Non-sale price behavior is broadly consistent with menu cost models of sticky prices. When we focus specifically on the behavior of sale prices, however, we find that the characteristics of price adjustment seems to be substantially 


\title{
Price setting in a leading Swiss online supermarket
}

\author{
Martin Berka* Michael B. Devereux ${ }^{\dagger}$ Thomas Rudolph $\ddagger \S$ \\ Massey University UBC, NBER, CEPR University \\ of St.Gallen
}

June 3, 2011

\begin{abstract}
We study a newly released data set of scanner prices for food products in a large Swiss online supermarket. We find that average prices change about every two months, but when we exclude temporary sales, prices are extremely sticky, changing on average once every three years. Non-sale price behavior is broadly consistent with menu cost models of sticky prices. When we focus specifically on the behavior of sale prices, however, we find that the characteristics of price adjustment seems to be substantially at odds with standard theory.
\end{abstract}

\section{Introduction}

In introductory micro-economic textbooks, prices adjust to equate supply and demand. When we move to macro-economics, we often qualify this assumption to allow for the possibility of sticky prices. According to this theory, firms face costs of frequently changing prices. As a result, they set prices in advance, and adjust them only at (ir)regular intervals, or in face of large shocks. Sticky prices form the core of New Keynesian approaches to macro-economic modeling. Despite the ubiquity of the sticky price assumption, until recently, there was little hard micro-economic evidence on the way in which prices adjust, the frequency at which they adjust, and the determinants of price adjustment. Following Bils and Klenow's (2004) seminal study of the US CPI micro data base however, there has been a rapid growth of new studies of micro price data ${ }^{1}$.

*Martin Berka, School of Economics and Finance, Massey University, POBox 102 904, NSMC, Auckland, New Zealand. Email: mberka@gmail.com

${ }^{\dagger}$ Michael B. Devereux, Department of Economics, UBC, 1873 East Mall, Vancouver, BC, V6T1Z1 Canada. Email: devm@interchange.ubc.ca

$\ddagger$ University of St. Gallen, Switzerland

§First draft: extremely preliminary. Devereux thanks SSHRC, the Royal Bank, and the Bank of Canada for financial support. The views in this paper are those of the authors alone and do not represent the views of the Bank of Canada.

${ }^{1}$ We discuss the empirical literature on micro price studies below 
One development within this literature is the use of scanner, or electronic price data. This is particularly attractive, because it gives the transactions price of an individual product (rather than a category) at very high frequency, so it comes as close as we can possibly get to the micro-economic concept of the sale price of an exact product. Scanner price data sets have been examined by Chevalier, Kashyap and Rossi (2003), Eichenbaum et al. (2011), Broda and Weinstein (2010), Kehoe and Midrigan (2010), and Chevalier and Kashyap (2011), among others (these papers are discussed more fully below).

So far however, most of the literature using scanner prices has focused on data sets from North America (US and Canada). While these results are of great importance, it may be that pricing behavior and characteristics from other countries give different results. This paper adds to this literature by looking at a new scanner price data set from a large on-line retail outlet in Switzerland. Our data cover a variety of food groups over a four year interval from 2004-2007.

Our findings present some interesting contrasts to the previous literature. We aggregate our real time data into weekly prices and quantities sold. As in the previous literature, we find that unconditionally, price changes are very frequent (on average, prices change every two months). But there is a huge difference between temporary price changes - changes which are reversed after one week (which we refer to as sales prices), and more permanent price changes - defined in our study as modal prices within a quarter, which we call reference prices, following Eichenbaum et al. (2011). Reference prices changes are extremely infrequent - in our data, on average, reference prices change only once every three years! Thus excluding sales, we find that prices are extremely sticky - significantly more so than in other studies.

We investigate the implications of our data for the relevance of standard menu cost models of price change. Menu cost models predict that the frequency of price change should be positively related to average inflation. As argued by Eichenbaum et al. (2011) and Kehoe and Midrigan (2010), the relevant prices for studying menu cost models should be reference prices, rather than actual prices. During the sample of our data set, Swiss CPI inflation was just under 2 percent and did not vary significantly on a year to year basis. However, we can investigate the implications of inflation at the individual product category level in determining variations in the frequency of price changes for each different category of product. Interestingly, for the food groups in our data set, CPI inflation in Switzerland was negative during the sample. But we find clear evidence that the higher the absolute level of inflation in a category, the higher the frequency of reference price changes.

In addition, we find that for reference prices, there is an unambiguous positive association between the frequency of reference price change and the absolute level of price changes, both for all prices, and for each category of product in our sample. The more often reference prices are adjusted, the larger is the size of the adjustment. It is not clear whether this observation represents a confirmation or a contradiction of standard menu cost pricing. If variation in the frequency of price adjustment is driven mostly by differences in the volatility of cost or demand, we should expect to see a positive association between size and frequency. If on the other hand, variation in the frequency of adjustment is mostly determined by variation in menu-costs, we should expect to see the opposite.

While recent literature has been careful about making the distinction between reference 
prices (or regular prices, in Kehoe and Midrigan's (2010) terminology) and actual prices, much less theoretical focus has gone into the explanation of temporary price changes, which represent the difference between reference prices and actual prices. The classic model of firm sales is due to Varian (1980). An important recent paper by Chevalier and Kashyap (2011) adapts Varian's model of sales in an empirical study of US scanner price data. They develop a number of clear predictions which follow from firm profit-maximizing determination of the frequency of sales. Sales should be important in determining the overall average selling price of a product - defined as the 'effective price'. Large sales, (involving substantial reductions in the price of the product) should be relatively infrequent. Finally, most sales should involve one product, and coincident sales of two or more products within a category should be relatively rare.

We use our data to investigate these implications of the theory of profit-maximizing sales. Our results are quite striking. We find strong contradictory evidence for all three predictions. Effective prices of products are very close to reference prices, and far above sales prices. There is a strong positive association between frequency of sales and size of sales. Goods that have more frequent sales also have larger sales. Finally, coincident sales of more than one product is substantially more common in the data than predicted by the theory. Hence, taken together, our results seem to throw substantial doubt on the standard theory of sales, leaving a puzzle over the understanding of sales frequency and size in our data.

The next section reviews some recent literature in micro pricing. Section 3 describes our data in detail. Following this, we describe the main characteristics of price adjustment in our data. Section 5 describes the characteristics of reference prices, and explores the implication for menu cost models. Section 6 discusses the behavior of sales prices and compares these to a theoretical model of sales. Some conclusions follow.

\section{Literature Review}

Our paper is related to a growing recent literature on micro price data. Since the valueadded of our paper is in the alternative data set, it is important to place our work in the context of the literature. The now seminal paper by Bils and Klenow (2004), using BLS monthly data for 1995-97 from the US CPI Research Database, finds that the median duration of prices that cover $70 \%$ of the CPI basket is less than 4.3 months, or 5.5 months excluding sales. They find that the duration of prices is highly heterogeneous, ranging from 80 months for coin-operated laundry to 0.6 months for gasoline. This contrasts with the previous consensus estimate of the price stickiness of about one year (Taylor, 1999). In contrast to their findings, calibrated versions of Calvo and Taylor sticky-price models tend overpredict inflation persistence and undepredict volatility.

Klenow and Kryvtsov (2008), using a longer span of BLS micro-data (1988-2004), document non-sale price changes of 4-7 months on average, and of an order of $10 \%$. Their findings are in fact close to ours. They find that both the size and probability of a price change are unrelated to the time since the last price change. This contrasts with our findings below. In addition, they find that aggregate inflation changes arise from changes in the size of price changes, rather than the frequency of price changes.

Nakamura and Steinsson (2008) document 5 "facts" gleaned from the BLS micro-data 
that can shed light on the relevance of standard menu cost models. They find that a) median non-sale price change frequency is half of sale frequency, b) a third of non-sale price changes are decreases, c) the frequency of price increases covaries strongly with inflation (but not the frequency of price decreases or the size of price changes), d) the frequency of price changes is highly seasonal, and d) there is no evidence of upward sloping hazard functions of price functions. Nakamura and Steinsson argue that only the first three facts are consistent with the menu cost models. Our findings are generally consistent with Nakamura and Steinsson, save for the extreme stickiness of non-sale prices in our data.

However, the ability of the BLS monthly micro-data to identify sales-related statistics remains a concern, given that sales in many retail outlets are offered at much higher than monthly frequency and given also the fact the BLS data describe an area or category rather than a single store or a product.

In contrast to CPI data, scanner price data give exact prices for transactions at the product level. Using scanner data, Chevalier, Kashyap and Rossi (2003) find that supermarket prices (Dominick's Finer Foods, Chicago area, 1989-1997) fall during seasonal demand peaks, as margins fall, a relationship which is consistent with "loss-leader" models of retailer competition but rules out manufacturer behavior as the main driver of this countercyclical price behaviour.

On the other hand, Eichenbaum et al. (2011) find that manufacturer behaviour plays an important role to the extent that it translates to fluctuations in supermarket costs. Using weekly scanner and cost data from a major US supermarket retailer, they document considerable inertia in non-sale prices, which they refer to as 'reference prices'. Reference prices are sticky for around one year. On the other hand, in their data set, prices including sales change on average every two weeks around their reference values. One advantage of the Eichenbaum et al. (2011) paper is that they have access to imputed costs as well as transactions prices. They argue that sticky costs are the main source of sticky reference prices. In addition, they find that reference prices are on average re-set so as to maintain mark-ups within $20 \%$ of their desired level.

Using AC Nielsen prices of 100 products in 7000 US stores of 33 chains in 2004, Nakamura (2008) decomposes variation in prices. She finds that $16 \%$ of it is common across stores, $65 \%$ is common within a chain (but not across chains) and $17 \%$ is idiosyncratic. She argues that such little comovement of prices of the same products across various chains diminishes the role of manufacture-level supply, and demand shocks, and contradicts menu cost models such as that of Golosov and Lucas (2007) and Klenow and Kryvtsov (2007).

There are relatively few explicit models of temporary price changes in the empirical literature. Kehoe and Midrigan (2010) extend a standard New Keynesian model to replicate both sales- and regular price- dynamics documented in the aforementioned literature. In their model, firms can deviate from a sticky pre-existing price if they incur a fixed cost. They do so in response to changes in production costs. However, temporary "micro" price changes cannot offset monetary policy shocks well, unlike the regular price changes. The low frequency of the regular changes leads to large real effects of monetary shocks, as well as a sticky aggregate price level in their model.

Chevalier and Kashyap (2011) present a model of price setting for substitutable products driven by the heterogeneity of consumer types, which highlights the importance of sales at a macroeconomic level. Retailers optimally chose pricing plans to optimally seg- 
ment "bargain-hunters" from the "loyal" buyers who have a strict preference of a brand in a range of substitutable products. The model's main prediction is that, because of the substituting behaviour by a number of buyers, effective prices are substantially below regular posted prices (which they confirm for a small sample of products). The model also predicts that sales should be evenly spaced apart and that sales that are more frequent should be of a smaller magnitude, and that sales should not be synchronized within groups of highly substitutable products.

Modelling of sales dates back at least to the seminal contribution of Varian (1980), with randomized pricing (hence sales) used optimally by retailer to segment between the informed and the uninformed buyers. One feature of Varian's model is a U-shaped price density function, which implies a positive relationship between the frequency and the size of the sale, unlike Chevalier and Kashyap (2011).

As described in the next section, our study is based on online scanner price data, which gives exact product description, time of sale, quantity and prices sold. Unlike Eichenbaum et al. (2010), we have a relatively small group of food product categories. But within these categories, we have a large number of individual products. In addition, as in Chevalier and Kashyap (2011), we can identify time and size of sales at the product level.

\section{Data-Description}

Our data-set contains 2068 bar codes of products in three categories: beverages, dairy and pasta. Aside from the bar code, each product has 5 classifications: main category, subcategory (15, including cocoa, coffee, ice tea, ...), sub-subcategory (101, including decaf coffee, ground coffee, instant coffee, etc.), and two additional classifications of which the last one contains the exact product description with weight or volume (e.g., Gatorade Fitness PET 75cl). The data-set contains transactions for these products in a four-year period from January 1, 2004 until December 31, 2007. Each transaction includes an exact time of purchase, bar code, price and quantity purchased.

We aggregate all transactions into weekly data. Our main results will relate to products that have more than one year of data, although we also report results for products with more than one month of data (the results differ little between the two sub-samples). Focusing on products with more than one year of data narrows our sample to 700 products, and a total of 1.12 million transactions (about 97,000 weekly data points), while in the second group (products with more than one month of data) there are 1177 separate products. Figure 1 plots sample paths of some of the products. As in many other price data, we see that there appear to be two quite separate types of price changes; relatively frequent reductions in prices which are reversed quickly, and more permanent changes in prices. These two different types of price change will form the focus for our discussion of this data set.

For the products with over one year of data, the mean duration of the product in the sample is 149.5 weeks or nearly 3 years. The majority of this sub-sample consists of products that are present for the full four year sample. Figure 2 plots the histogram of durations for these products. Goods in the one-year or above sample cover all main categories and 77 subcategories. 


\section{Frequency of price changes}

Our main interest is the way in which prices change. A price change is defined as an event where there is a difference in price from one week to the next, including prices that are reversed after a short time. Table 1 documents the features of price changes for the full group of products as well as for the 3 main subcategories. For all products together, the monthly frequency of price change is .453 , implying that on average prices change every 2.2 months, or 5.5 times per year. This indicates a reasonably frequent degree of price change, which is in line with other literature (e.g. Eichenbaum et al. 2010). But behind this average, there is a large degree of heterogeneity in the frequency of price changes across products. The standard deviation of the monthly frequency of price change in the sample is .332. This implies a range of price adjustment from every 1.2 months to every 8.3 months. There are 38 products whose prices change less than once a year and 35 products which change price at least 12 times a year. Figure 3 plots the distribution of the number of price changes per month. With weekly data, monthly frequency exceeds 1 if a product's price changes at least once a month (which as noted is the case for 35 products). The maximum feasible frequency of price changes in a month with weekly data is 4 , as there are 4.33 weeks in a month on average. In our data, the maximum frequency is 1.64, while the minimum is 0 (which is the case for 17 products).

Table 1 also breaks down the sample frequencies into the three main categories. Our sample (of products with more than 1 year of data) contains 418 products in the category of beverages, 207 products in dairy and 75 products in pasta. The average sample length is 154 weeks for beverages, 145 weeks for dairy and 129 weeks for pasta. Yoghurt prices tend to change least frequently, on average every 2.4 months, followed by beverages $(2.25)$ and pasta (1.6). However, frequency of price changes of pasta is most disperse. Figure 4 summarizes this information.

We further separate the products into 12 level-two categories. The average rate of price adjustment varies from every 1.6 months for pasta to every 12.5 months for tea. Table 2 shows summary statistics for all categories. Figure 5 plots data time coverage by category (from a low average of 117 weeks for Energy drinks to a high of 142 weeks for Syrups), and Figure 6 plots the distributions of monthly price change frequencies.

Finally we separate the products into 54 level-three categories. Table 3 provides summary statistics. The number of products within level-three category varies from 1 (in 7 cases) to 47 for energy drinks. The average monthly frequency of price changes varies from from 0.08 for Black tea to 0.99 for Barilla pasta. The average price changes by the level-three category are nearly as disperse as all price change frequencies, with the mean $\mathrm{CV}$ of price change frequencies of 0.44 .

There is also a varying degree of heterogeneity of price change frequencies within levelthree categories (the last column of Table 3). The coefficient of variation within each category is between 0.1 for Nectar juice, (and by construction also 0 for all single-product categories) to 1.3 for Migros Pasta.

The last column of Table 1 reports the proportion of all price changes that were price increases. Slightly over half of price changes were price increases on average over all categories, and a similar result applies for each category. Again, this reflects the fact that a lot of price changes in the data were temporary price reductions. We now discuss the nature of these price changes in more detail. 


\subsection{Temporary Prices and Reference Prices}

While the frequency of price changes is relatively high when we look at all price changes, we also recognize from Figure 1 that many price changes are quickly reversed. The recent empirical pricing literature has acknowledged the importance of separating temporary price changes from price changes that are not reversed. Temporary price changes are associated with sales or promotions that are not necessarily part of the longer term price markup calculations that firms undertake. Accordingly, we separate these two different types of price change. We define a temporary price change (or a sale) as any price change which lasts just one week, where the price after one week returns to the original price ${ }^{2}$. As can be seen in the examples of Figure 1, there are many such instances of temporary price changes in the data. We argue below that the interpretation of temporary price changes as sales is appropriate for our data, since in almost all cases, these price changes involve a fall in price which is later reversed.

These temporary price changes do not seem to affect the 'permanent' price of the product however. Following Eichenbaum et al. (2011), we refer to this latter price as the 'reference price'. In our data set, we define the reference price for any product as the modal price within each calendar quarter. Reference prices therefore omit temporary price changes by construction. As discussed by Eichenbaum et al. (2011), we can think of reference prices as the relevant price that is determined by the firm's longer term profit maximization.

Figure 7 and Table 4 show the equivalent measures of price change frequency as Figure 2 and Table 1, but now for the reference prices for each category. The first and major fact to note is that there is an extreme degree of price stickiness in reference prices. The average monthly frequency of changes in reference prices is 0.027 (for products with at least 1 year of data). As we saw above, the average monthly frequency of changes in all prices is 0.45 (the medians are 0.021 and 0.42 , respectively). This contrasts sharply with the findings in the US data. Bils and Klenow (2004) document median duration of prices of 4.3 months, or 5.5 months excluding sales. Eichenbaum et al. (2011) find median duration of price changes in supermarket scanner data of about 3 weeks for all prices, but nearly 1 year for reference prices. Our median durations obtained by the simple inversion are 37 months (3 years) for reference prices and 2.2 months for all prices ${ }^{3}$.

The extreme price stickiness for reference prices is uniform across the three categories. Again there is some degree of heterogeneity - the standard deviation of price change frequencies for all products is 0.034 , implying mean durations varying from 20 months to infinity . Across categories there is also heterogeneity - again with Pasta having the highest frequency of price changes. Nonetheless, for all categories, the frequency of price change for reference product prices is an order of magnitude lower than that for actual prices, and much lower than in other studies.

Because we do not have data on costs, we cannot calculate the degree to which the

\footnotetext{
${ }^{2}$ There are some but very few examples of temporary two week price changes. We omit these from our measure, since they do not affect any of the results

${ }^{3}$ Note that for very low price change frequencies, simple inversion under-estimates true duration (see Baharad and Eden 2004). This implies that prices are even more sticky than suggested here when duration measures are calculated correctly (to be updated in next draft).
} 
seller allows reference price markups to vary over time in face of variation in costs. The data set used in Eichenbaum et al. (2011) does have cost data, however, and finds a considerable degree of markup variation even when reference prices have a much higher frequency of price change than in our data. This would make it highly unlikely that reference price stickiness is reflecting constancy of marginal costs.

What is the average direction of change in reference prices? Table 4 shows that on average, price changes for reference prices were positive. Over 60 percent of price changes were price increases. This is what we would expect in an environment with positive average inflation. Interestingly however, CPI inflation rates corresponding to the three products in our sample were negative during the sample period. CPI inflation rates for Switzerland for the products categories over the sample period were negative, for all three categories. Monthly inflation rates for Beverages and Yoghurts over the sample averaged at $-0.02 \%$, while average monthly inflation for Pasta was $-0.014 \%$. Thus, on average, relative reference prices seem to have been rising over time.

How large are price changes in these data? Table 5 reports on the size of price changes, conditional on prices changing. For all price changes, the average absolute price change is 11.4 percent (median 10.8) percent. There is some variation across categories in this respect, with price changes for yoghurts being 14.8 percent, while price changes for beverages being 9.7 percent. As is clear from the illustrations in Figure 1, temporary price reductions are often countered by exactly offsetting price increases. The mean price increase in the data is 11.9 percent, while the mean price decrease is 11.5 percent. For reference prices, the size of price increases and decreases is smaller. Moreover, the size of decreases in the reference price is larger than the size of increases, and more importantly, the median price change is significantly lower than the mean price change. This aspect of the data is developed further below when we look at the relationship between size and frequency of price change.

To help comparison with previous studies, Table 6 compares the basic properties of reference prices in our dataset with two scanner datasets; that of Eichenbaum et al. (2011), and the Dominicks data set used also in Eichenbaum et al. (2011) and in Kehoe and Midrigan (2010). In our data, the reference price is substantially more commonly applied in transactions. Prices are at the reference price almost 90 percent of the time, compared with 62 percent in Eichenbaum et al. (2011) and 77 percent in the Dominicks data set. More striking, the reference price does not change in 56 percent of all quarters in the data. In Eichenbaum et al (2011) and Dominicks data set, the equivalent number is 10 and 19 percent, respectively. This underscores the large difference in the degree of price rigidity in our data set and other scanner price data series. In addition, over 80 percent of quantities are sold at the reference price, and over 80 percent of revenue is collected at the reference price; substantially more than in the other data sets. We return to this issue in section 6 below when we discuss 'effective prices'. Finally, in our data, essentially all non-reference prices are below the reference price. In the two other data-sets, over one quarter of deviations from the reference price lead to prices above the reference price. This strongly supports our interpretation of temporary departures from non-reference price as sales. In section 6 below, we explore in more detail the nature of sales in our data. 


\section{Reference Prices and Menu Cost Models}

In traditional macroeconomic models of sticky prices, the assumption is that it is costly for a firm to alter the nominal selling price of its product. Time dependent models assume an alternation between periods of infinite costs of price change and other periods with zero costs.of price change. State-dependent models assume that firms always face some cost of changing its nominal price (its 'menu cost'), and chooses to alter its price when the benefit from doing so outweighs the menu cost.

Neither time or state dependent models can accurately capture the characteristics of price adjustment described in our data set. Many price change quite frequently, clearly undermining the idea that there are many periods where the firm cannot change its price. But this also seems to invalidate the assumption that the firm has a fixed menu cost of nominal price change and therefore would conserve on costs by keeping the nominal price constant for long periods. The fact is that in scanner price data, it is hard to argue for the literal existence of costs of changing the menu of posted prices, and the presence of substantial episodes of temporary price change suggests that menu costs in a literal sense cannot account for the behaviour of prices.

The proposed resolution of this puzzle has been to apply the idea of menu costs not to the behavior of all prices, but to the changes in the regular or reference prices. So Eichenbaum et al (2011), Guamaires and Sheedy (2011), and Kehoe and Midrigan (2010) argue that the appropriate prices relevant for menu cost models are prices that have been purged of temporary price changes, equivalent to our reference prices. In these papers, the standard menu cost models are augmented in ways so that firms choose both a reference price (or price plan, or target price) and at higher frequencies choose to allow prices to temporarily deviate from this plan. In Eichenbaum et al. (2011), the firm chooses a price plan that determines the reference price over a fixed interval, and then chooses whether to engage in temporary departures from the reference price due to idiosyncratic cost shocks, within the life of the reference price. In Guamaires and Sheedy (2011), different groups of consumers have different elasticities of demand for a firms product. As a result, there are multiple prices over which a firm may profit maximize, and firms engage in a mixed strategy over the setting of these prices. In their model, average prices within a period are set as in Calvo (1983). In Kehoe and Midrigan (2010), there is a distinction between 'regular price' and 'posted price'. They assume that there is a fixed cost of changing regular prices and another cost of changing posted prices. One common aspect of all three papers is that the influence of aggregate macro shocks should be seen in reference prices (or regular prices), which change at lower frequencies than actual prices.

Given this reinterpretation of price stickiness, it is reference prices rather than all prices that should be consistent with standard menu cost models. What are the characteristics of menu-cost models, and how do the relate to the observable characteristics of reference prices in our data? The standard menu cost model (e.g. Sheshinski and Weiss 1977, Gertler and Leahy, 2008, Golosov and Lucas, 2007) predicts that firms change prices infrequently, at irregular intervals that depends on both aggregate and idiosyncratic shocks. The observable features of the data relate to the frequency and size of price changes, and to the degree of asymmetry between price increases and decreases. The frequency of price change should be greater, the higher is the aggregate rate of inflation. Higher aggregate inflation should also increase the absolute size of price changes, since with higher inflation, 
once prices change, they have to adjust by more. In addition, higher variability in either demand or cost shocks should increase the frequency of price changes, at the same time as increasing the absolute size of price changes. It should increase the frequency, since in standard Ss type pricing models (e.g. Sheshinski and Weiss 1977) more volatile demand or cost will involve hitting the upper and lower bands for price adjustment more often. At the same time, higher positive or negative shocks should involve more absolute price adjustment. On the other hand, if variations in the frequency of price adjustment across different products or firms is determined primarily by variation in the size of the menu cost, then we should anticipate to see a negative relationship between frequency and size of price adjustment, since a small (large) menu cost will involve frequent (infrequent) but small (large) price adjustments.

How do these predictions of menu cost models apply to our data on reference prices? The impact of aggregate inflation on the frequency of price change represents a time series channel, and there is not a sufficiently long sample or enough variation in aggregate Swiss inflation to test this causal linkage. We can alternatively look at differential inflation rates across the products categories based on disaggregated CPI data by products groups. Specifically, we obtain category- specific CPI series for each of the main categories in our data, over the same sample as our data coverage. Movements in aggregate CPI categories may be thought of as roughly proxying for category-specific costs facing the firm. Higher average inflation in each category should then be associated with more frequent reference price adjustment by category.

Table 7 and Figure 8 illustrate the relationship between inflation and frequency of price change. From the Swiss CPI, we obtained data on 8 CPI groups which closely accord with equivalent categories in our sample. The Table shows, for each category, summary statistics for the CPI for that category, and summary statistics for monthly reference price change frequency in that category.

As we see, all 8 CPI categories exhibit negative average monthly inflation rates over the sample. The most negative are pasta and "cocoa and similar drinks", at $-0.15 \%$ per month on average. The correlation of average monthly inflation and average monthly reference price change frequency is -0.69 .. The negative correlation applies because inflation rates are negative. Note however that three of the categories in the Table have either one or two products in them. If we drop these, the correlations becomes -0.97 .

Although this is just a small sample of all our data, it does suggest that reference product prices change more frequently for products with higher inflation rates. This is what we would expect from a menu cost model, if category inflation rates act as a proxy for costs.

Now, let us address the relationship between size and frequency of reference price changes. Figure 9 illustrates the relationship between the absolute size of reference price changes and the frequency of reference price change in our data, both for the full sample, and by individual categories of products. The results are quite unambiguous. There is a strong positive correlation between size of reference price changes and frequency of reference price change. Goods whose reference prices change more frequently also have higher absolute percentage reference price changes. Table 8 indicates that this relationship is highly significant. It reports results from a regression of frequency of reference price change with average absolute percentage reference price change. Figure 9 also makes clear that this relationship holds across individual categories of products. 
This relationship suggest that to the extent that the menu cost model is an appropriate interpretation of reference price changes, differences in the frequencies of reference price change are driven by differences in the volatility of cost or demand shocks, and not by differences in the cost of price change. Recall that if heterogeneity in frequency of price change were principally generated by heterogeneity in menu costs, we would see the opposite relationship between size and frequency.

This discussion is based on the assumption that reference prices, rather than observed prices, are the relevant variable for understanding the menu cost model. But even if we took the view that all price changes (and not just reference prices) were the more relevant variables in the relationship between size and frequency of price changes, we will show below that we still get the same positive relationship between frequency and size.

\section{Temporary Price Changes}

Let us now focus on temporary price changes. Recall that we define these as episodes where the price changes for a one week period, and then goes back to the original level for the next week ${ }^{4}$. Table 6 established that 96 percent of non-reference prices are below the contemporaneous reference price. Clearly therefore, we may think of temporary price changes away from the reference price as sales prices. .And we have seen that price changes coming from sales are far more common than reference price changes.

It is also the case that price changes associated with sales are typically bigger than reference price changes. As noted in Table 4, the median price increase and decrease for all prices is around 11 percent, while the corresponding changes for references prices are 5 and 7 percent.

We have already discussed the reason why the typical menu cost model should probably not be applied to the analysis of sales. From the observations of frequent sales, it seems hard to argue that there are substantial costs to the firm of reducing the nominal price of a product for purposes of a sale. But then what theory should be used to understand sales? The classic model of sales in economics is developed in Varian (1980). A recent paper by Chevalier and Kashyap (2011) adapts Varian's modeling framework along an empirical dimension to analyse the occurrence of sales in scanner price data. In their model, there are two types of consumers. 'Loyal' consumers purchase their favorite brand in every period and never substitute for other products. 'Bargain hunters' on the other hand are willing to substitute across products and moreover, do not necessarily make a purchase in every period. They can wait for a sale price of a product within a given category of products and then buy in bulk. Their model predicts two key features of the data. First, 'effective prices' of a product, defined as the average of the price at which the product is purchased where the averaging is over sales and non-sales purchases, is considerably lower than the regular price (which is the reference price in our terminology). Secondly, sales of similar brands (or, in our terminology, products within narrowly defined categories) tend not to be coincident - a firm will typically offer a sale price on only one product within a category at any moment in time, ensuring that it will absorb the accumulated demand from bargain hunters for this category, while at the same time maintaining a

\footnotetext{
${ }^{4}$ There are some instances of two week price changes. In the current version of the paper, we ignore those events. None of the results discussed here are affected by the absence of two week price changes.
} 
high price paid from the loyal costumers for other products within the category. A third prediction of the model is that more frequent sales tend to involve less price discounting (smaller reductions in price relative to the regular price). The intuition is as follows. Bargain hunters have a lower valuation for any product relative to loyal consumers, and are willing to wait to consume the product. If the valuation difference is quite small, then sale price reductions are small, but sales are quite frequent, since they are quite lucrative (they absorb demand from shoppers at a rather high price). But if shoppers have a very low valuation of the product, it is necessary to have large sales. In this case, the sales are quite infrequent, since it is necessary to have a lot of accumulated demand before the sale becomes profitable. Hence, the model predicts a clear negative association between the frequency of sales and the size of price reductions in sales.

We now examine how these predictions are borne out in our data. Beginning with the last prediction, Figure 10 plots the relationship between the size of price changes for sale prices and the frequency of sale price change. Just as in the case of reference prices, there is a clear positive relationship between size of price changes and the frequency of price change. That is, products that have more frequent sales have also larger sales. This is confirmed in Table 8, where the relationship between size and frequency across products is seen to be highly statistically significant. Hence, our data seem to be sharply at variance with the theory of sales based on using price reductions as a device to absorb accumulated demand on the part of bargain hunting consumers. If this were the case, we'd expect to see the opposite relationship between frequency and size; infrequent sales would be associated with extreme bargain hunters, and would therefore involve very substantial discounts relative to the regular price.

The next question concerns the relationship between the sales price and the "effective price'. Given that sales prices are on average 11 percent below the reference price, then we would infer that the effective price would be somewhere in between the reference price and 11 percent below the reference price. As argued by Chevalier and Kashyap (2011), sales are an essential part of the price plan if the effective price is substantially below the regular price. We measure the effective price by the average price actually paid for each product, by combining transaction price and quantity sold for each product over the full sample. Table 9 illustrates that the median effective price over all products is somewhat less than 2 percent below the reference price. Figure 11 plots the distribution of effective price discounts over the whole sample. Thus, the reference price does not, on average give a significantly misleading view of the effective price for products. When broken down into different categories, we find some heterogeneity. The median effective price for pasta involves a larger discount of 2.7 percent. In comparison to Chevalier and Kashyap, our results indicate a much smaller difference between reference prices and the effective price.

The final prediction we look at is the degree of coincidence of sales for products within narrowly defined categories. Recall that the theory predicts a preponderance of single product sales. Here we also find quite striking contradictions to the predictions of the standard model. Broadly speaking, we find that sales tend to come in groups. When one product within a category experiences a sale, then so do the other products, at least much more so than would occur if sales in products were chosen independently. This represents a striking contrast to the Dominicks scanner data examined by Chevalier and Kashyap (2011).

Following Chevalier and Kashyap (2011), our approach is as follows. For each cate- 
gory of products, imagine that there $\mathrm{N}$ separate products. Over the sample, each product $j \in N$ has a sale with frequency $p_{j}<1$. If sales of a particular product within a category were completely independent, then for each category, then at each period, we would have zero sales with probability $\Pi_{j}^{N}\left(1-p_{j}\right)$, sale of product $N$ only with probability $\Pi_{j=1}^{N-1}\left(1-p_{j}\right) p_{N}$, sale of product $N-1$ only with probability $\Pi_{j=1}^{N-2}\left(1-p_{j}\right)\left(1-p_{N}\right) p_{N-1}$, sale of product $N$ and $N-1$ with probability $\Pi_{j=1}^{N-2}\left(1-p_{j}\right) p_{N-1} p_{N}$ etc. Thus, we can conduct a full frequency distribution for zero, single, and multiple coincident sales using the independence assumption We can then compare this with the observed incidence of zero, single and multiple sales over the sample, for each category of products. In the model of Chevalier and Kashyap, if sales are chosen to maximize profits, balancing the loyal shoppers against the bargain hunters, then the incidence of single product sales will be greater than that predicted by the independent distribution, and the incidence of zero and multiple product sales will be less than that predicted by the independent distribution.

Figure 12 and Table 10 illustrate these results. Strikingly, Figure 11 strongly rejects the model predictions. The incidence of single product sales in the data is below that predicted by an independent distribution, for every category of product, while the incidence of zero, or more than two coincident sales is above the independent distribution. For coincident sales of two products only, the results are evenly mixed, with 16 categories having two-product sales with frequency less than that predicted by the independent distribution, and 16 having two-product sales more than predicted by the independent distribution.

Table 10 illustrates the same data by each category of product. The conclusion we arrive at from both Figure and Table is that within categories, the firm tends to combine sales of products. There are many instances where multiple products, or even all products, are on sale at the same time. For categories within multiple products, this would be very unlikely if sales were determined independently across products, and would be a measure zero observation if we take the model literally. But taking a more general interpretation, the finding that one product sales occur far less often than predicted by the independent distribution seems to undermine the theory of sales based on the differentiation of loyal consumers from strategic bargain hunters.

\section{Conclusions}

We have provided a first pass at analyzing the behaviour of micro prices from scanner data at a large European outlet. Compared to other studies, prices are substantially more sticky in our data. While references prices do seem to accord with implications of menu-cost models, the behavior of sales prices seems not to be well explained by standard theory.

Our study obviously has its limitations. We are focusing only one a relatively narrow category of products, and all products pertain to just a single retail online firm. Nevertheless, within this category of products, there are a large number of different products, and the coverage is at very high frequency, over a substantial time period. In addition, the online retailer who provided the data have a market share of approximately 70 percent of the Swiss grocery online market. So the price data are significantly representative of 
the Swiss CPI. Hence, the results can throw some light on the nature of price adjustment in retail sales, the importance of sticky prices, and the relevance of sales prices for macroeconomic models.

\section{References}

[1] Eyal Baharad and Benjamin Eden. Price rigidity and price dispersion: evidence from micro data. Review of Economic Dynamics, 7(3):613-641, July 2004.

[2] Mark Bils and Peter J. Klenow. Some evidence on the importance of sticky prices. Jornal of Political Economy, 112(5):947-985, October 2004.

[3] Christian Broda and David E. Weinstein. Product creation and destruction: Evidence and price implications. American Economic Review, 100(3):691-723, June 2010.

[4] Guillermo A. Calvo. Staggered prices in a utility-maximizing framework. Journal of Monetary Economics, 12:383-398, September 1983.

[5] Judith Chevalier and Anil K. Kashyap. Best prices. Working Paper 16680, NBER, January 2011.

[6] Judith A. Chevalier, Anil K. Kashyap, and Peter E. Rossi. Why don't prices rise during periods of peak demand? evidence from scanner data. American Economic Review, 93(1):15-37, March 2003.

[7] Martin Eichenbaum, Nir Jaimovich, and Sergio Rebelo. Reference prices, costs and nominal rigidities. American Economic Review, 101(1):234-262, February 2011.

[8] Mark Gertler and John Leahy. A Philips curve with an Ss foundation. Journal of Political Economy, 116(3):533-572, June 2008.

[9] Mikhail Golosov and Robert E. Lucas Jr. Menu costs and Philips curves. Journal of Political Economy, 115(2):171-199, April 2007.

[10] Bernardo Guimaraes and Kevin D. Sheedy. Sales and monetary policy. American Economic Review, 101(2):844-876, April 2011.

[11] Lorraine Ivancic, W. Erwin Diewert, and Kevin J. Fox. Scanner data, time aggregation and the construction of price indexes. Journal of Econometrics, 161:24-35, March 2011.

[12] Patrick J. Kehoe and Virgiliu Midrigan. Prices are sticky after all. Working Paper 16364, NBER, September 2010.

[13] Peter J. Klenow and Oleksiy Kryvtsov. State-dependent or time-dependent pricing: does it matter for refent U.S. inflation? Quarterly Journal of Economics, 123:863904, August 2008.

[14] Emi Nakamura. Pass-through in retail and wholesale. American Economic Review, 98(2):430-437, May 2008. 
[15] Emi Nakamura and Jon Steinsson. Five facts about prices: a re-evaluation of menu cost models. Quarterly Jouranal of Economics, 123(4):1415-1464, November 2008.

[16] Emi Nakamura and Jon Steinsson. Monetary non-neutrality in a multi-sector menu cost model. Quarterly Jouranal of Economics, 125(3):961-1013, August 2010.

[17] Eytan Sheshinski and Yoram Weiss. Inflation and costs of price adjustment. The Review of Economic Studies, 44(2):287-303, June 1977.

[18] John B. Taylor. Handbook of Macroeconomics, volume 1, Part B, chapter Staggered price and wage setting in macroeconomics, pages 1009-1050. Elsevier, 1999.

[19] Hal R. Varian. A model of sales. American Economic Review, 70(4):651-659, September 1980 .

\section{Tables}

Table 1: All-price descriptive statistics (monthly frequencies)

\begin{tabular}{|c|c|c|c|c|c|c|c|c|c|c|}
\hline \multirow[b]{3}{*}{$\begin{array}{l}\text { Category } \\
\text { name }\end{array}$} & 1 & 2 & 3 & 4 & 5 & 6 & 7 & 8 & 9 & 10 \\
\hline & \multicolumn{5}{|c|}{ Products with at least 1 month of data } & \multicolumn{5}{|c|}{ Products with at least 1 year of data } \\
\hline & $\begin{array}{c}\# \\
\text { prod. }\end{array}$ & $\begin{array}{c}\text { Mean } \\
\Delta P \text { freq }\end{array}$ & $\begin{array}{l}\text { Median } \\
\Delta P \text { freq }\end{array}$ & $\begin{array}{c}\text { STD } \\
\Delta P \text { freq. }\end{array}$ & $\begin{array}{c}\text { Prop. of } \\
\text { P incr. }\end{array}$ & $\begin{array}{c}\# \\
\text { prod. }\end{array}$ & $\begin{array}{c}\text { Mean } \\
\Delta P \text { freq }\end{array}$ & $\begin{array}{l}\text { Median } \\
\Delta P \text { freq }\end{array}$ & $\begin{array}{c}\text { STD } \\
\Delta P \text { freq. }\end{array}$ & $\begin{array}{c}\text { Prop. of } \\
\text { P incr. }\end{array}$ \\
\hline All & 1177 & 0.383 & 0.300 & 0.423 & 0.522 & 700 & 0.453 & 0.417 & 0.332 & 0.523 \\
\hline Beverages & 696 & 0.387 & 0.299 & 0.466 & 0.524 & 418 & 0.444 & 0.398 & 0.346 & 0.526 \\
\hline Yogurts & 369 & 0.348 & 0.273 & 0.324 & 0.515 & 207 & 0.412 & 0.357 & 0.244 & 0.511 \\
\hline Pasta & 112 & 0.474 & 0.462 & 0.415 & 0.530 & 75 & 0.619 & 0.538 & 0.407 & 0.530 \\
\hline
\end{tabular}

Table 2: Level-2 categories and summary statistics

\begin{tabular}{lcc|cc|ccc}
\hline \hline Category & $\begin{array}{c}1 \\
\text { No. of } \\
\text { prod. }\end{array}$ & $\begin{array}{c}\text { Avg. } \\
\text { weeks }\end{array}$ & $\begin{array}{c}\text { Mean monthly } \\
\Delta P \text { freq. }\end{array}$ & $\begin{array}{c}\text { CV } \\
\text { of } \Delta P\end{array}$ & $\begin{array}{c}5 \\
\text { Avg. } \\
\# \Delta P_{R}\end{array}$ & $\begin{array}{c}\text { Avg. } \\
\Delta P_{R} \text { freq. }\end{array}$ & $\begin{array}{c}\text { CV } \\
\text { of } \Delta P_{R}\end{array}$ \\
\hline Cocoa & 1 & 68 & 0.32 & 0.00 & 2.00 & 0.13 & 0.00 \\
Coffee & 2 & 57.5 & 0.40 & 0.93 & 1.00 & 0.08 & 0.14 \\
Energy drinks & 47 & 119.4 & 0.39 & 0.57 & 1.17 & 0.04 & 0.81 \\
Ice tea & 41 & 177.7 & 0.34 & 0.93 & 1.32 & 0.03 & 1.16 \\
Juices & 127 & 140.7 & 0.52 & 0.50 & 1.07 & 0.03 & 1.14 \\
Mineral water & 82 & 135.2 & 0.59 & 0.63 & 0.98 & 0.03 & 1.35 \\
Sodas & 63 & 165.2 & 0.47 & 0.72 & 1.29 & 0.03 & 0.72 \\
Syrups & 32 & 142.3 & 0.41 & 0.35 & 1.00 & 0.04 & 0.96 \\
Tea & 2 & 56.5 & 0.08 & 1.41 & 0.50 & 0.04 & 1.41 \\
Yoghurts & 186 & 168.4 & 0.49 & 0.59 & 0.72 & 0.02 & 1.18 \\
Curd Yoghurts & 18 & 71.2 & 0.31 & 0.93 & 0.00 & 0.00 & NaN \\
Pasta & 70 & 151.3 & 0.64 & 0.49 & 2.63 & 0.07 & 0.82 \\
\hline \hline
\end{tabular}


Table 3: Level-3 category summary statistics

\begin{tabular}{|c|c|c|c|c|c|c|c|c|}
\hline $\begin{array}{l}\text { Category } \\
\text { name }\end{array}$ & $\begin{array}{c}1 \\
\text { No. of } \\
\text { prod. }\end{array}$ & $\begin{array}{c}2 \\
\text { Avg. no. } \\
\text { of weeks }\end{array}$ & $\begin{array}{c}3 \\
\text { Avg. no. } \\
\text { of } \Delta P \mathrm{~s}\end{array}$ & $\begin{array}{c}4 \\
\text { Mean monthly } \\
\Delta P \text { freq. }\end{array}$ & $\begin{array}{c}5 \\
\mathrm{CV} \\
\text { of } \Delta P\end{array}$ & $\begin{array}{c}6 \\
\operatorname{Avg} . \\
\hat{\beta} \\
\end{array}$ & $\begin{array}{c}7 \\
\text { Median } \\
\hat{\beta}\end{array}$ & $\begin{array}{c}8 \\
\text { Avg. } \\
\left|t_{\hat{\beta}}\right|\end{array}$ \\
\hline Instant Cocoa & 1 & 68.0 & 5.0 & 0.3 & 0.0 & 5.6 & 5.6 & 2.4 \\
\hline Decaf & 1 & 52.0 & 8.0 & 0.7 & 0.0 & -2.6 & -2.6 & 1.4 \\
\hline Ground & 1 & 63.0 & 2.0 & 0.1 & 0.0 & -3.9 & -3.9 & 0.2 \\
\hline Energy Drinks & 47 & 119.4 & 11.4 & 0.4 & 0.6 & -0.2 & -1.6 & 2.4 \\
\hline Lemon & 17 & 186.9 & 13.6 & 0.3 & 1.0 & -6.7 & -6.7 & 6.1 \\
\hline Light & 6 & 206.7 & 21.8 & 0.5 & 0.8 & -4.0 & -4.8 & 5.7 \\
\hline Peach & 18 & 159.3 & 12.9 & 0.3 & 1.0 & -2.1 & -4.8 & 4.7 \\
\hline Apple & 14 & 126.2 & 15.4 & 0.6 & 0.5 & -12.6 & -5.9 & 5.6 \\
\hline Fresh Fruit & 23 & 145.9 & 18.0 & 0.5 & 0.3 & -5.3 & -3.9 & 6.5 \\
\hline Grapefruit & 6 & 112.7 & 14.2 & 0.5 & 0.5 & -4.1 & -5.0 & 3.6 \\
\hline Kids Drink & 7 & 146.1 & 10.0 & 0.3 & 0.7 & -3.4 & -2.1 & 4.5 \\
\hline Multi Fruit & 24 & 161.7 & 20.8 & 0.6 & 0.5 & -3.9 & -4.3 & 6.1 \\
\hline Nectar & 8 & 121.6 & 18.6 & 0.7 & 0.1 & -5.4 & -5.2 & 5.3 \\
\hline Orange & 18 & 142.9 & 17.3 & 0.6 & 0.6 & -6.4 & -4.3 & 5.9 \\
\hline Other Fruit & 16 & 133.4 & 12.1 & 0.4 & 0.5 & -3.6 & -5.5 & 5.0 \\
\hline Pineapple & 7 & 155.4 & 18.4 & 0.5 & 0.8 & -3.3 & -3.7 & 6.0 \\
\hline Vegetable & 4 & 99.8 & 11.0 & 0.4 & 0.7 & -0.8 & -3.9 & 3.4 \\
\hline Flavoured & 35 & 106.2 & 13.5 & 0.6 & 0.6 & -38.3 & -4.9 & 4.8 \\
\hline Sparkling & 22 & 168.3 & 27.2 & 0.7 & 0.7 & -5.0 & -4.4 & 6.8 \\
\hline Still & 25 & 146.5 & 18.6 & 0.5 & 0.5 & -3.8 & -4.0 & 5.6 \\
\hline Colas & 17 & 155.1 & 14.3 & 0.4 & 0.7 & -0.3 & -2.0 & 4.8 \\
\hline Lemonades & 39 & 163.8 & 21.7 & 0.6 & 0.6 & -2.0 & -4.6 & 7.3 \\
\hline Tonic Bitter & 7 & 197.1 & 6.9 & 0.1 & 0.5 & 14.2 & 8.8 & 5.9 \\
\hline Other Fruit & 1 & 68.0 & 6.0 & 0.4 & 0.0 & 0.2 & 0.2 & 0.2 \\
\hline Syrups & 31 & 144.7 & 14.2 & 0.4 & 0.4 & -6.0 & -6.7 & 4.3 \\
\hline Black Tea & 2 & 56.5 & 1.0 & 0.1 & 1.4 & -24.9 & -24.9 & 1.2 \\
\hline Bio & 4 & 155.3 & 19.0 & 0.6 & 0.2 & -3.5 & -3.7 & 4.9 \\
\hline Danone & 23 & 148.0 & 13.8 & 0.4 & 0.3 & -3.6 & -3.8 & 3.8 \\
\hline Drinks & 15 & 178.3 & 18.7 & 0.5 & 0.5 & -3.7 & -3.5 & 6.9 \\
\hline Emmi & 18 & 117.9 & 7.1 & 0.3 & 0.2 & -4.2 & -6.1 & 4.4 \\
\hline greek & 6 & 139.5 & 14.2 & 0.5 & 0.3 & -3.0 & -2.9 & 3.5 \\
\hline Hirz & 30 & 185.6 & 40.3 & 0.9 & 0.1 & -3.7 & -3.4 & 9.5 \\
\hline Lactosefree & 2 & 206.0 & 15.0 & 0.3 & 0.2 & -0.2 & -0.2 & 2.4 \\
\hline $\mathrm{LC} 1$ & 21 & 157.4 & 30.1 & 0.8 & 0.2 & -3.7 & -3.7 & 7.4 \\
\hline migrosexcellence & 5 & 185.8 & 18.8 & 0.4 & 0.2 & -1.5 & -1.5 & 2.4 \\
\hline migrosheidi & 4 & 125.0 & 3.5 & 0.1 & 1.2 & -6.6 & -8.8 & 0.9 \\
\hline migrosprobifidus & 5 & 120.4 & 5.4 & 0.2 & 0.6 & -0.2 & -0.4 & 0.9 \\
\hline migrosslimline & 1 & 54.0 & 9.0 & 0.7 & 0.0 & -0.4 & -0.4 & 1.0 \\
\hline migrosstandard & 17 & 203.4 & 14.9 & 0.3 & 0.2 & -1.9 & 0.1 & 2.4 \\
\hline mueslis & 6 & 198.7 & 10.5 & 0.2 & 0.3 & -2.1 & -1.5 & 1.4 \\
\hline petitsuisse & 8 & 176.9 & 9.0 & 0.2 & 0.6 & 0.9 & -2.4 & 4.6 \\
\hline Toni & 21 & 201.4 & 14.0 & 0.3 & 0.2 & -6.9 & -6.8 & 7.1 \\
\hline Bio & 4 & 89.0 & 5.0 & 0.3 & 0.6 & -0.5 & -0.4 & 1.0 \\
\hline Danone & 1 & 62.0 & 8.0 & 0.6 & 0.0 & -5.4 & -5.4 & 4.2 \\
\hline Hirz & 3 & 57.3 & 10.3 & 0.8 & 0.3 & -3.0 & -3.0 & 5.0 \\
\hline Migros & 7 & 66.4 & 2.7 & 0.2 & 1.3 & -0.3 & 0.0 & 0.4 \\
\hline Mesli & 3 & 75.7 & 2.3 & 0.1 & 0.4 & -2.0 & -2.5 & 1.0 \\
\hline Barilla & 1 & 63.0 & 2.0 & 0.1 & 0.0 & 11.2 & 11.2 & 1.3 \\
\hline Barilla & 18 & 188.7 & 42.0 & 1.0 & 0.3 & -5.4 & -5.2 & 10.6 \\
\hline De Cecco & 10 & 171.8 & 27.2 & 0.7 & 0.2 & -4.1 & -4.3 & 6.7 \\
\hline MBudget & 4 & 164.3 & 11.3 & 0.3 & 0.4 & -9.4 & -9.6 & 5.9 \\
\hline Pasta without gluten & 3 & 57.7 & 5.7 & 0.4 & 0.3 & -3.0 & -2.6 & 1.6 \\
\hline Specialties & 18 & 84.7 & 7.26 & 0.4 & 0.4 & -10.9 & -5.9 & 3.4 \\
\hline TipoM 2 & 16 & 191.0 & 26.3 & 0.6 & 0.2 & -3.3 & -3.5 & 9.0 \\
\hline Average & 12.4 & 134 & 13.8 & 0.44 & 0.44 & -3.86 & -3.43 & 4.2 \\
\hline
\end{tabular}


Table 4: Reference price descriptive statistics ( $P_{R}$ is the modal quarterly price)

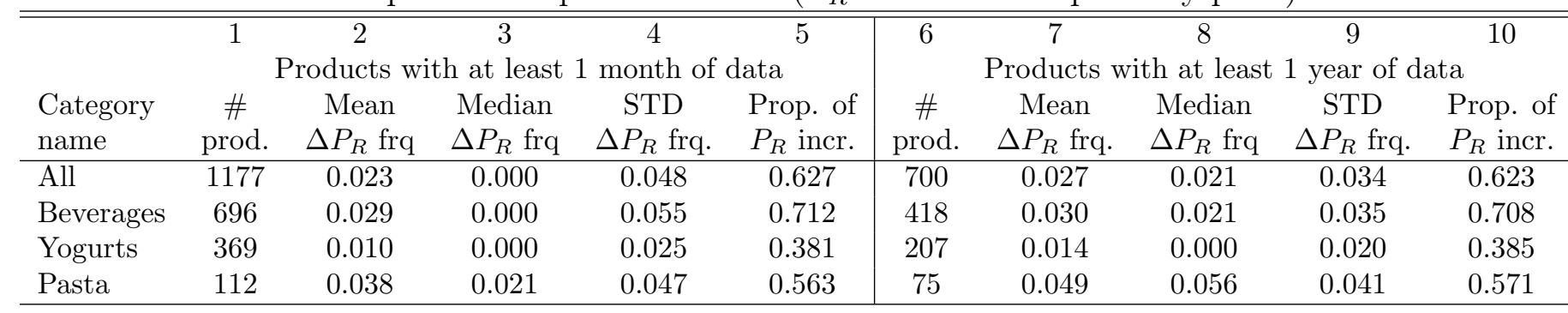

Table 5: Sizes of price changes (conditional on price change)

\begin{tabular}{|c|c|c|c|c|c|c|c|}
\hline $\begin{array}{l}\text { Category } \\
\text { name }\end{array}$ & $\begin{array}{c}1 \\
\text { No. of } \\
\text { prod. }\end{array}$ & $\begin{array}{c}2 \\
\text { Mean } \\
|\% \Delta P|\end{array}$ & $\begin{array}{c}3 \\
\text { Median } \\
|\% \Delta P| \\
\end{array}$ & $\begin{array}{c}4 \\
\text { Mean } \\
\% \Delta P>0 \\
\end{array}$ & $\begin{array}{c}5 \\
\text { Median } \\
\% \Delta P>0\end{array}$ & $\begin{array}{c}6 \\
\text { Mean } \\
\% \Delta P<0\end{array}$ & $\begin{array}{c}7 \\
\text { Median } \\
\% \Delta P<0\end{array}$ \\
\hline \multicolumn{8}{|c|}{ All prices } \\
\hline All & 654 & 11.4 & 10.8 & 11.9 & 11.2 & -11.5 & -11.0 \\
\hline Beverages & 386 & 9.7 & 9.7 & 10.2 & 10.0 & -10.1 & -9.9 \\
\hline Yogurts & 198 & 14.8 & 14.0 & 15.3 & 14.2 & -14.5 & -13.6 \\
\hline Pasta & 70 & 10.9 & 11.2 & 11.8 & 11.4 & -10.4 & -11.1 \\
\hline \multicolumn{8}{|c|}{ Reference prices } \\
\hline All & 404 & 8.2 & 4.5 & 8.7 & 4.3 & -10.7 & -6.7 \\
\hline Beverages & 252 & 7.2 & 4.0 & 6.7 & 2.9 & -11.5 & -9.1 \\
\hline Yogurts & 98 & 9.8 & 4.5 & 14.1 & 5.4 & -9.1 & -4.5 \\
\hline Pasta & 54 & 10.1 & 8.5 & 11.8 & 8.6 & -11.3 & -9.9 \\
\hline
\end{tabular}

Table 6: Basic statistics

\begin{tabular}{lccc}
\hline \hline Basic statistics & Le Shop & EJR & Dominicks \\
\hline Fraction of weeks spent at the reference price & 0.88 & 0.62 & 0.77 \\
Fraction of quarters in which weekly prices are constant for the whole quarter & 0.56 & 0.10 & 0.19 \\
Fraction of non-reference prices that are above reference prices & 0.04 & 0.25 & 0.30 \\
Fraction of price changes from a non-reference to reference price & 0.38 & 0.32 & 0.41 \\
Fraction of quantities sold at reference prices & 0.81 & 0.50 & 0.66 \\
Fraction of revenue collected at reference prices & 0.83 & 0.56 & 0.68 \\
\hline \hline
\end{tabular}

Table 7: Inflation and $P_{R}$ change frequency and size

\begin{tabular}{lccccccc}
\hline \hline & $\begin{array}{c}\text { Mean mon. } \\
\text { CPI cat. }\end{array}$ & $\begin{array}{c}2 \\
\text { STD mon. } \\
\text { name }\end{array}$ & $\begin{array}{c}\text { \# prod. in }(\%) \\
\text { category }\end{array}$ & $\begin{array}{c}\text { Mean } \\
\operatorname{pr}\left(\Delta P_{R}\right)\end{array}$ & $\begin{array}{c}\text { Median } \\
\operatorname{pr}\left(\Delta P_{R}\right)\end{array}$ & $\begin{array}{c}\text { STD } \\
\operatorname{pr}\left(\Delta P_{R}\right)\end{array}$ & $\begin{array}{c}\text { Mean abs. \% } \\
P_{R} \text { size change }\end{array}$ \\
\hline Pasta & -0.15 & 2.03 & 70 & 0.07 & 0.06 & 0.05 & 10.07 \\
Other milk & -0.02 & 0.66 & 204 & 0.02 & 0.00 & 0.02 & 9.84 \\
Coffee & -0.01 & 1.53 & 2 & 0.08 & 0.08 & 0.01 & 0.96 \\
Tea & -0.01 & 0.69 & 2 & 0.04 & 0.04 & 0.06 & 1.28 \\
Cocoa \& similar drinks & -0.16 & 2.65 & 1 & 0.13 & 0.13 & 0.00 & 5.06 \\
Mineral Water & -0.03 & 0.91 & 82 & 0.03 & 0.00 & 0.04 & 9.65 \\
Soft drinks & -0.05 & 0.49 & 154 & 0.04 & 0.04 & 0.03 & 5.52 \\
Fruit and veg juices & -0.03 & 0.77 & 156 & 0.03 & 0.02 & 0.04 & 8.72 \\
\hline \hline
\end{tabular}


Table 8: Positive relationship between absolute \% size of $d(P)$ and $d(P)$ frequency

\begin{tabular}{|c|c|c|c|c|c|c|c|c|c|c|c|c|c|c|c|c|}
\hline & \multicolumn{6}{|c|}{ All prices } & \multicolumn{6}{|c|}{ Modal prices } & \multicolumn{4}{|c|}{ Sales prices } \\
\hline & (1) & (2) & (3) & (4) & (5) & (6) & (7) & (8) & (9) & $(10)$ & $(11)$ & (12) & (13) & (14) & (15) & (16) \\
\hline $\mathrm{C}$ & 9.6 & 14.2 & 11.6 & 9.5 & 12.3 & -11.9 & 5.2 & 7.3 & 6.6 & 4.1 & 7.5 & -7.7 & 3.4 & 4.6 & 4.1 & 2.7 \\
\hline & $(14.8)$ & (19) & (16) & (15) & (13) & $(-20)$ & $(6.6)$ & $(7.6)$ & $(7.3)$ & $(4.8)$ & $(5.6)$ & $(-5.9)$ & $(8.0)$ & (10) & $(9.1)$ & (6.3) \\
\hline Freq. & $\begin{array}{c}0.24 \\
(4.96)\end{array}$ & $\begin{array}{l}0.25 \\
(5.5)\end{array}$ & $\begin{array}{c}0.23 \\
(5)\end{array}$ & 0.51 & 0.28 & $\begin{array}{l}-0.14 \\
(-3.6)\end{array}$ & 2.48 & $\begin{array}{l}3.07 \\
(5.2)\end{array}$ & 2.46 & 7 & 2.77 & $\begin{array}{l}-2.28 \\
(-3.2)\end{array}$ & 1.15 & $\begin{array}{l}1.37 \\
(78)\end{array}$ & 1.28 & 2.56 \\
\hline $\mathrm{D}_{b}$ & & $\begin{array}{l}-6.9 \\
(-10)\end{array}$ & & & $(4.0)$ & $(-3.0)$ & & $\begin{array}{c}-4 \\
(-3.9)\end{array}$ & & $(0.4)$ & & & & $\begin{array}{l}-2.2 \\
(-4.5)\end{array}$ & & \\
\hline $\mathrm{D}_{p}$ & & $\begin{array}{c}-5.8 \\
(-5.2)\end{array}$ & & & & & & $\begin{array}{c}-3.4 \\
(-2.1)\end{array}$ & & & & & & $\begin{array}{c}-4.2 \\
(-5.2)\end{array}$ & & \\
\hline $\mathrm{D}_{b} *$ freq & & & & $\begin{array}{c}-0.37 \\
(-7)\end{array}$ & & & & & & $\begin{array}{c}-4.5 \\
(-4.2)\end{array}$ & & & & & & $\begin{array}{l}-1.3 \\
(-5.5)\end{array}$ \\
\hline $\mathrm{D}_{p} *$ freq & & & & $\begin{array}{l}-0.31 \\
(-4.2)\end{array}$ & & & & & & $\begin{array}{c}-4.1 \\
(-4.3)\end{array}$ & & & & & & $\begin{array}{l}-2.3 \\
(-7)\end{array}$ \\
\hline $\operatorname{mean}(\mathrm{P})$ & & & $\begin{array}{l}-0.36 \\
(-5.9) \\
\end{array}$ & & $\begin{array}{l}-0.43 \\
(-5.4)\end{array}$ & $\begin{array}{c}0.28 \\
(5.7)\end{array}$ & & & $\begin{array}{l}-0.22 \\
(-3.1)\end{array}$ & & $\begin{array}{l}-0.38 \\
(-3.9)\end{array}$ & $\begin{array}{c}0.02 \\
(0.18) \\
\end{array}$ & & & $\begin{array}{l}-0.19 \\
(-4.2)\end{array}$ & \\
\hline adj. $R^{2}$ & 0.035 & 0.17 & 0.085 & 0.1 & 0.07 & 0.064 & 0.048 & 0.077 & 0.67 & 0.08 & 0.1 & 0.03 & 0.08 & 0.14 & 0.11 & 0.17 \\
\hline $\mathrm{N}$ & 654 & 654 & 654 & 654 & 652 & 631 & 404 & 404 & 404 & 404 & 309 & 228 & 488 & 448 & 488 & 488 \\
\hline
\end{tabular}

Dependant variable (except in (5),(6),(11),(12)) is the mean absolute percentage price change, conditional on a change. In (5) and (11), it is

the average percentage price increase, while in (6) and (12), mean percentage price decrease. $D_{b}$ and $D_{p}$ are dummy variables for beverages

and pasta. $t-$ stats are reported in parentheses. Significance of all coefficients does not depend on correction for heteroskedasticity.

Table 9: Effective prices

\begin{tabular}{|c|c|c|c|c|c|c|c|c|}
\hline $\begin{array}{l}\text { Category } \\
\text { name }\end{array}$ & $\begin{array}{c}1 \\
\text { Mean EP } \\
\% \text { discount }\end{array}$ & $\begin{array}{c} \\
\text { Median EP } \\
\% \text { discount }\end{array}$ & $\begin{array}{c}3 \\
\text { Mean \% } \\
\operatorname{STD}\left(P_{R}\right)\end{array}$ & $\begin{array}{c}4 \\
\text { Mean \% } \\
\operatorname{STD}(\mathrm{EP})\end{array}$ & $\begin{array}{c}5 \\
\text { Mean \% STD, } \\
\text { (EP discount) }\end{array}$ & $\begin{array}{c}6 \\
\text { Median \% } \\
\operatorname{STD}\left(P_{R}\right)\end{array}$ & $\begin{array}{c}7 \\
\text { Median \% } \\
\text { STD }(\mathrm{EP})\end{array}$ & $\begin{array}{c}8 \\
\text { Median \% STD, } \\
\text { (EP discount) }\end{array}$ \\
\hline All & 1.9 & 1.5 & 12.8 & 19.8 & 3.2 & 2.6 & 10.8 & 3.0 \\
\hline Beverages & 1.7 & 1.3 & 15.3 & 22.3 & 3.2 & 3.9 & 11.4 & 2.9 \\
\hline Yogurts & 2.2 & 1.6 & 8.4 & 15.4 & 3.1 & 2.2 & 7.0 & 3.1 \\
\hline Pasta & 1.9 & 1.9 & 8.7 & 15.2 & 4.0 & 4.3 & 12.2 & 3.6 \\
\hline
\end{tabular}




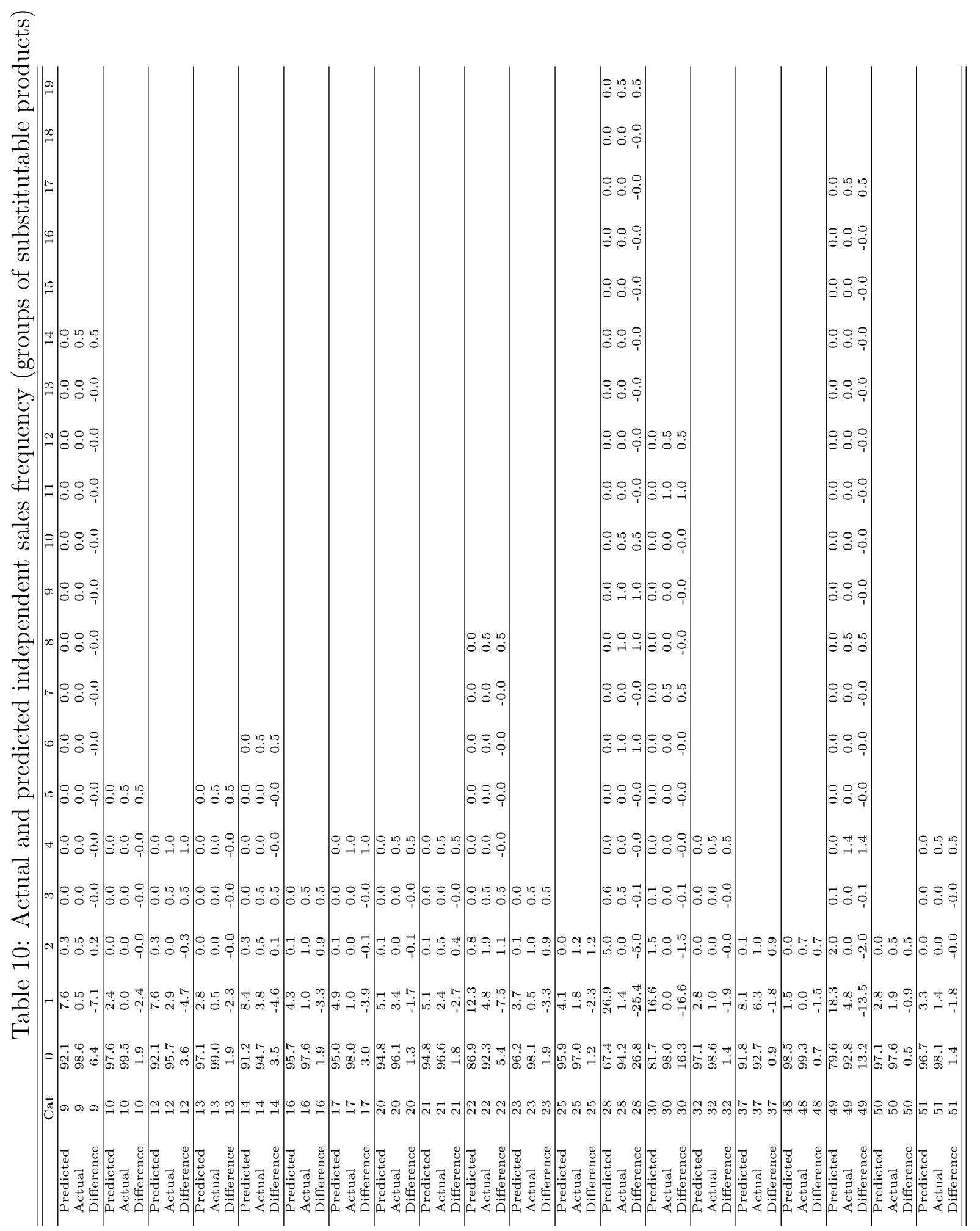




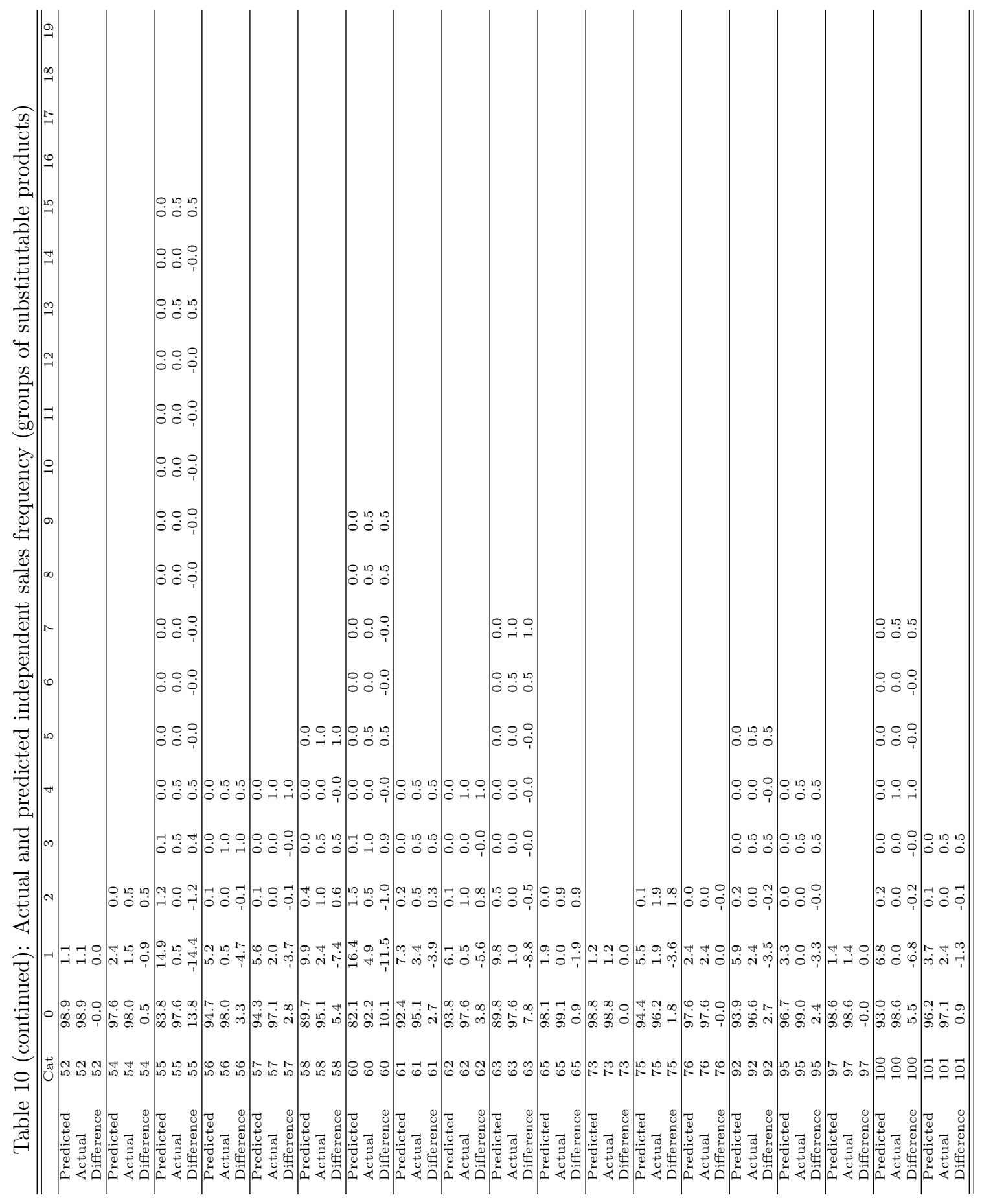




\section{$9 \quad$ Figures}

Figure 1: Example of weekly price series
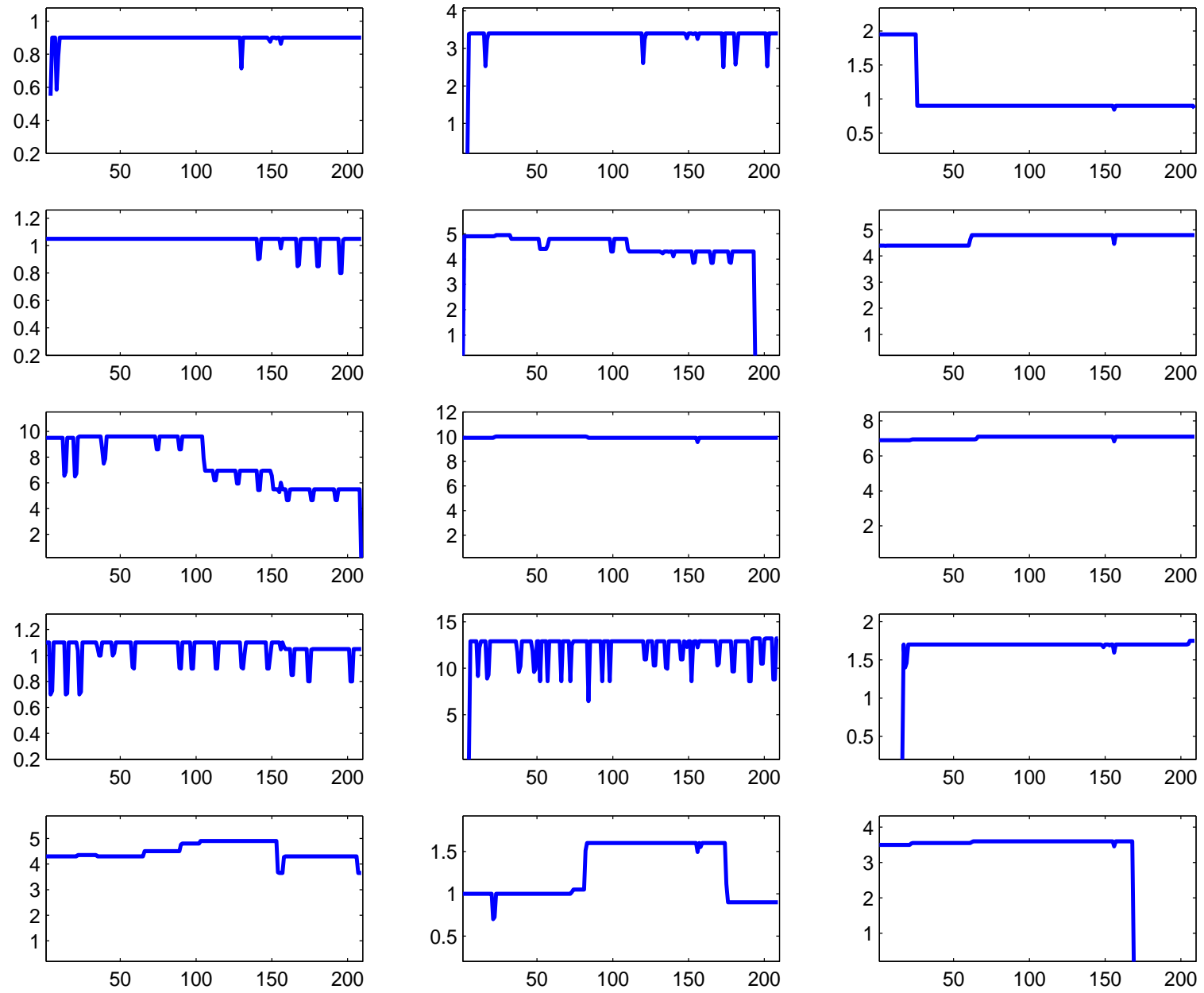
Figure 2: Distribution of sample lengths across 671 products

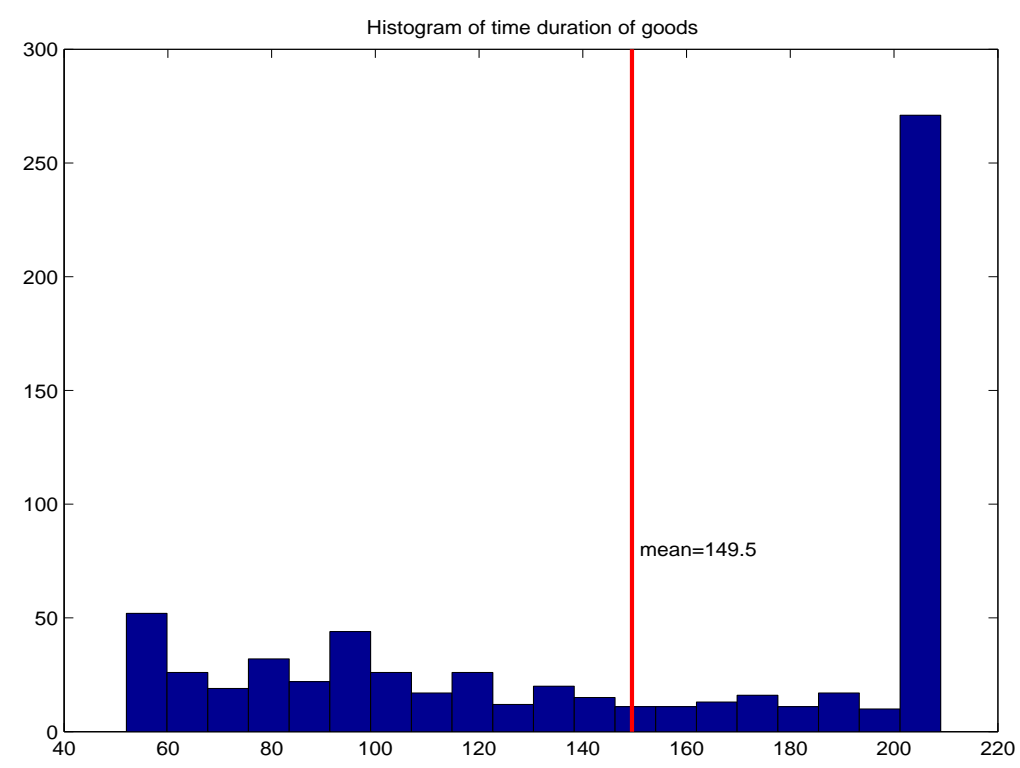

Figure 3: Distribution of price changes across 671 products

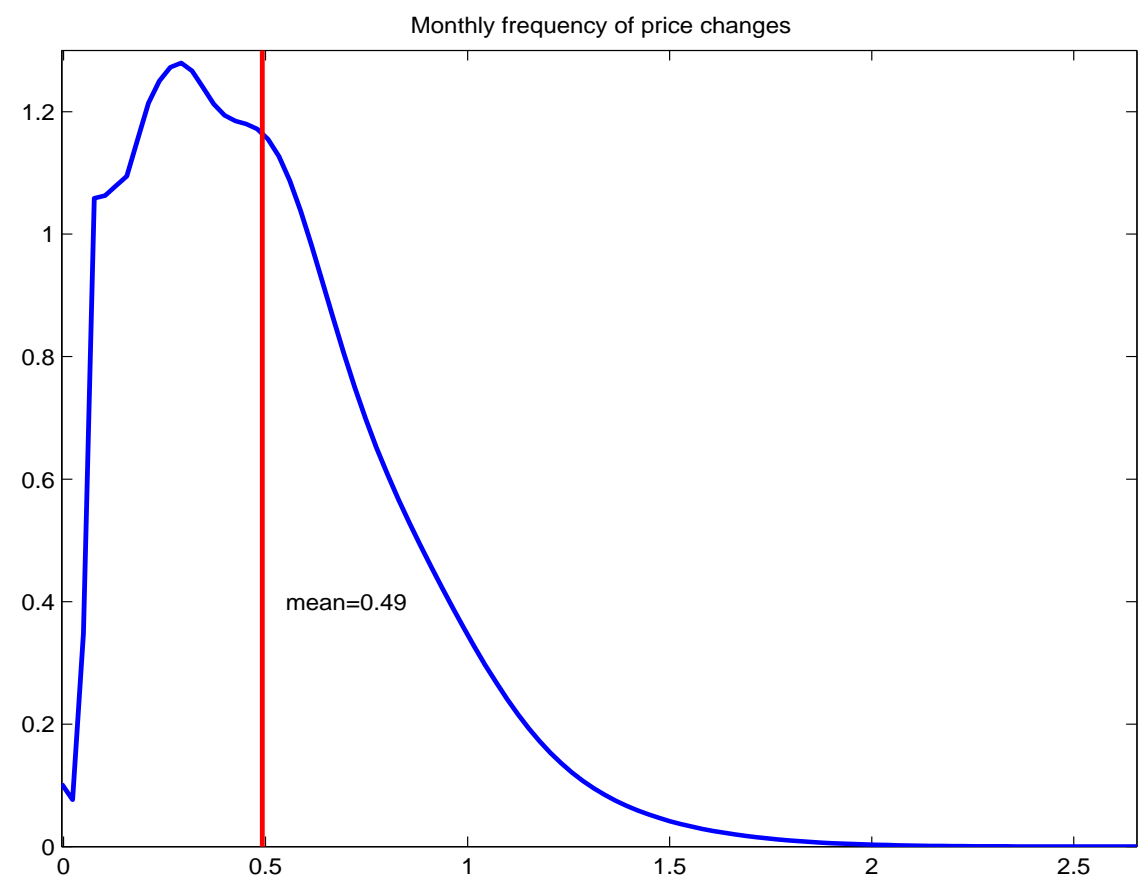


Figure 4: Time coverage and frequency of price and reference price changes for 3 main categories
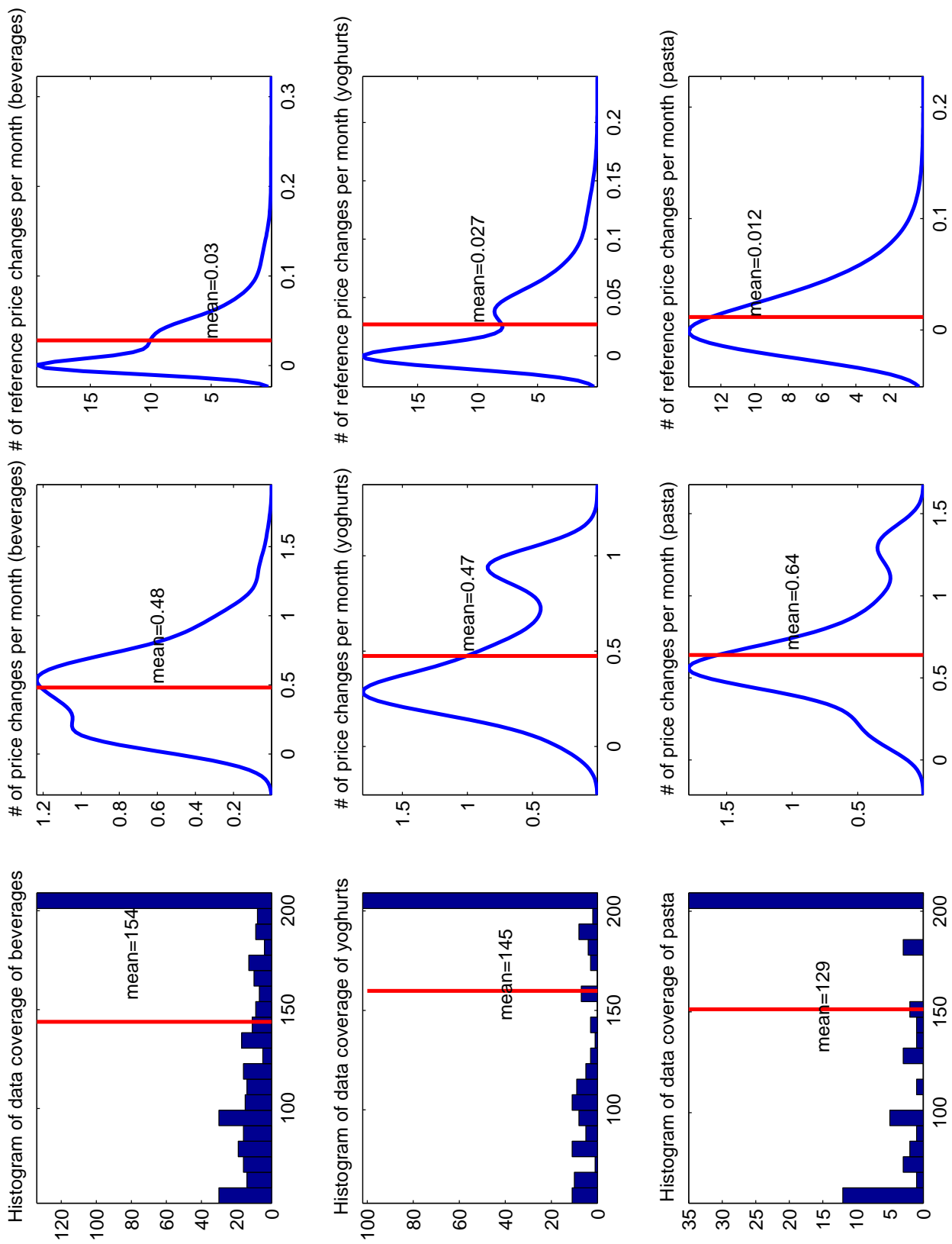
Figure 5: Time data coverage by level-2 category (weeks on horizontal axis)
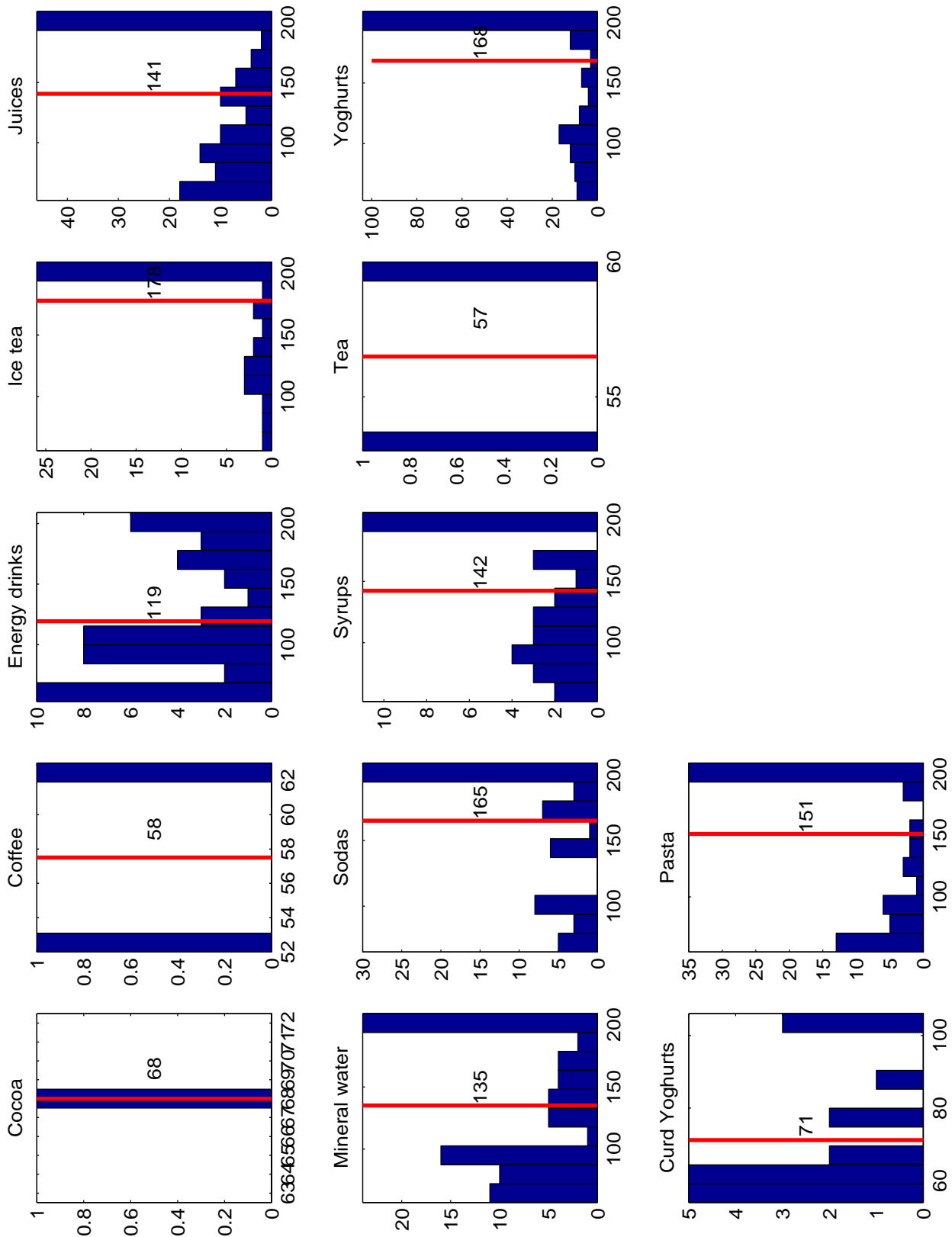
Figure 6: Frequency of annual price changes by level-2 category
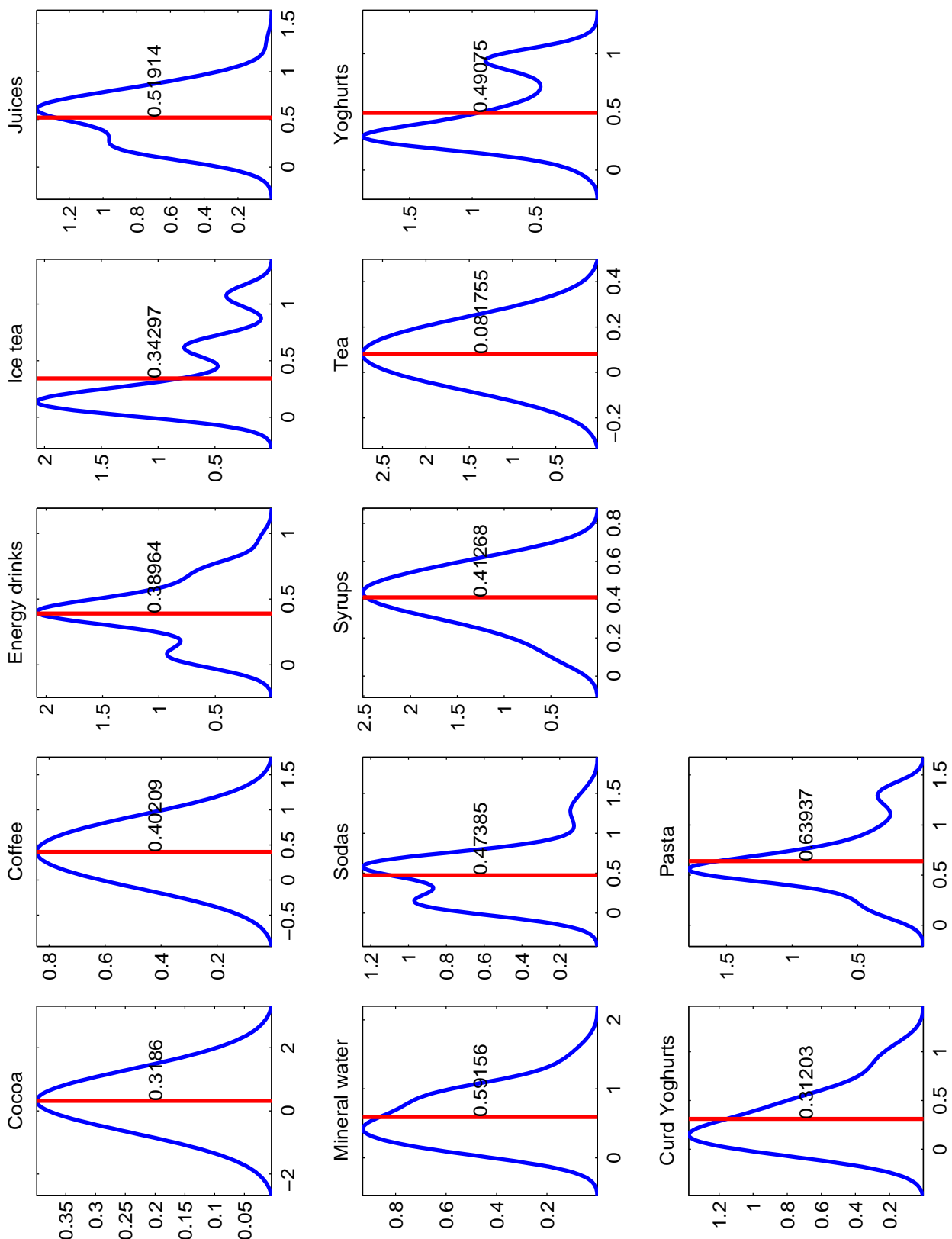
Figure 7: Distribution of reference price changes across 671 products

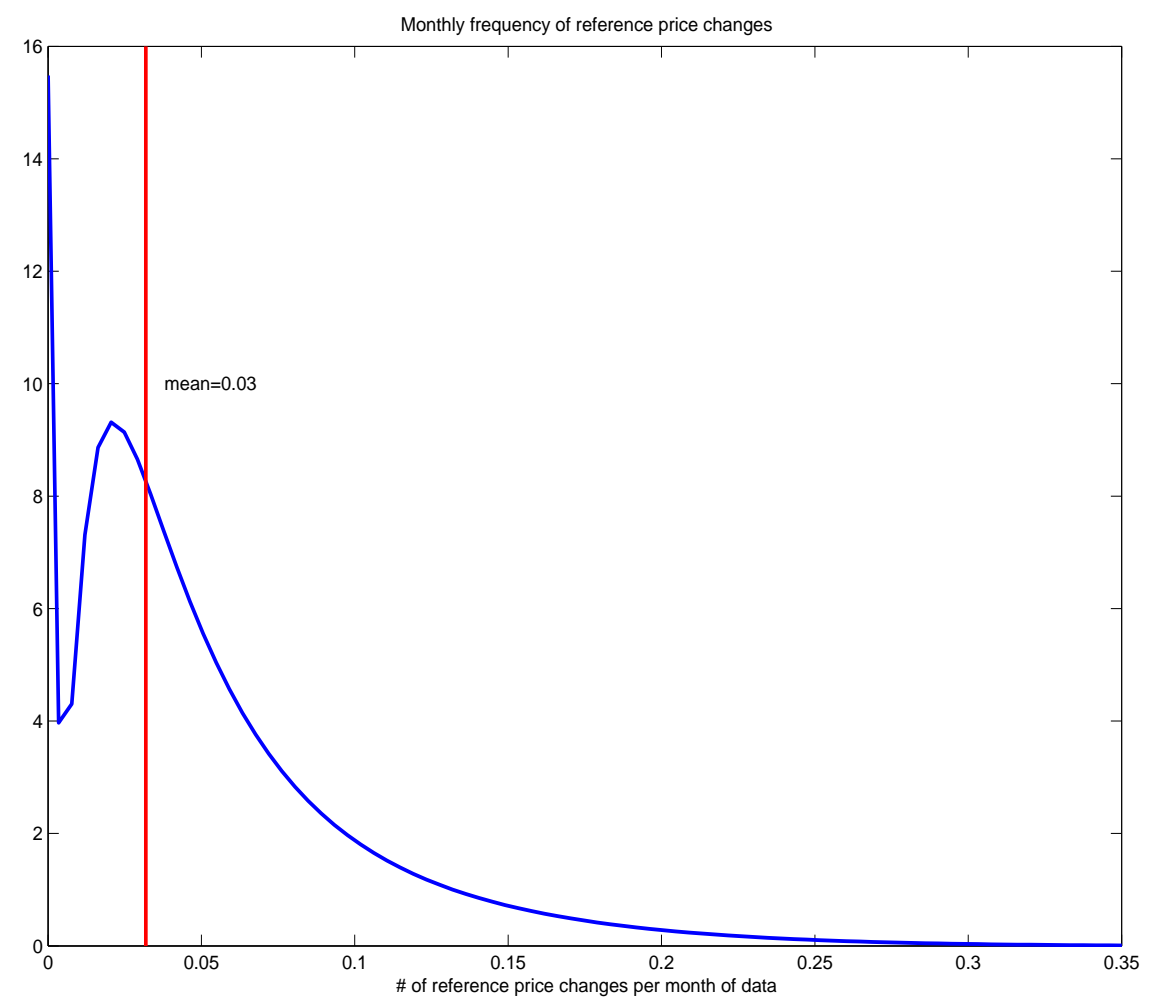


Figure 8: Mean monthly inflation and frequency of reference price changes

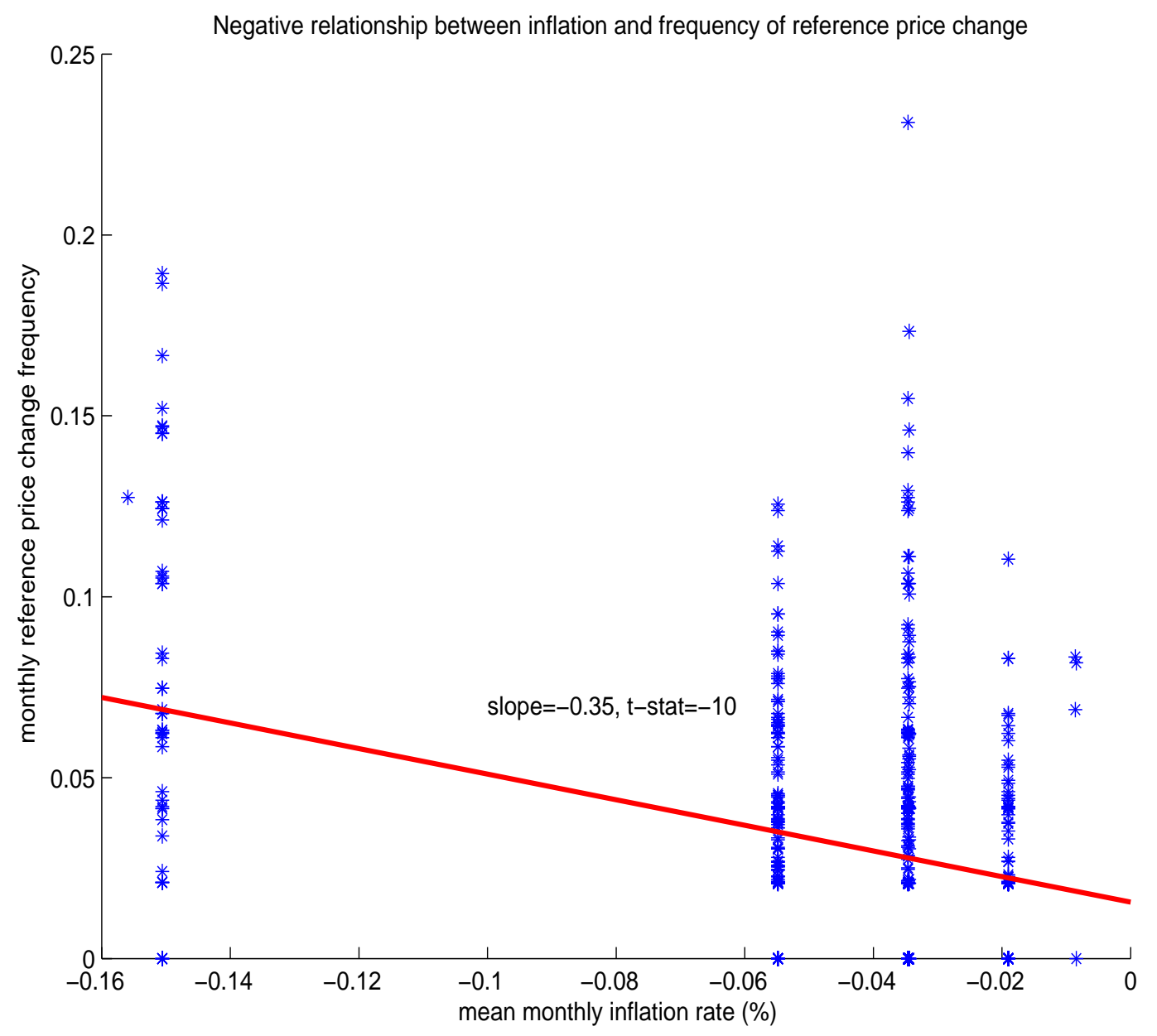


Figure 9: Size and frequency of reference price changes
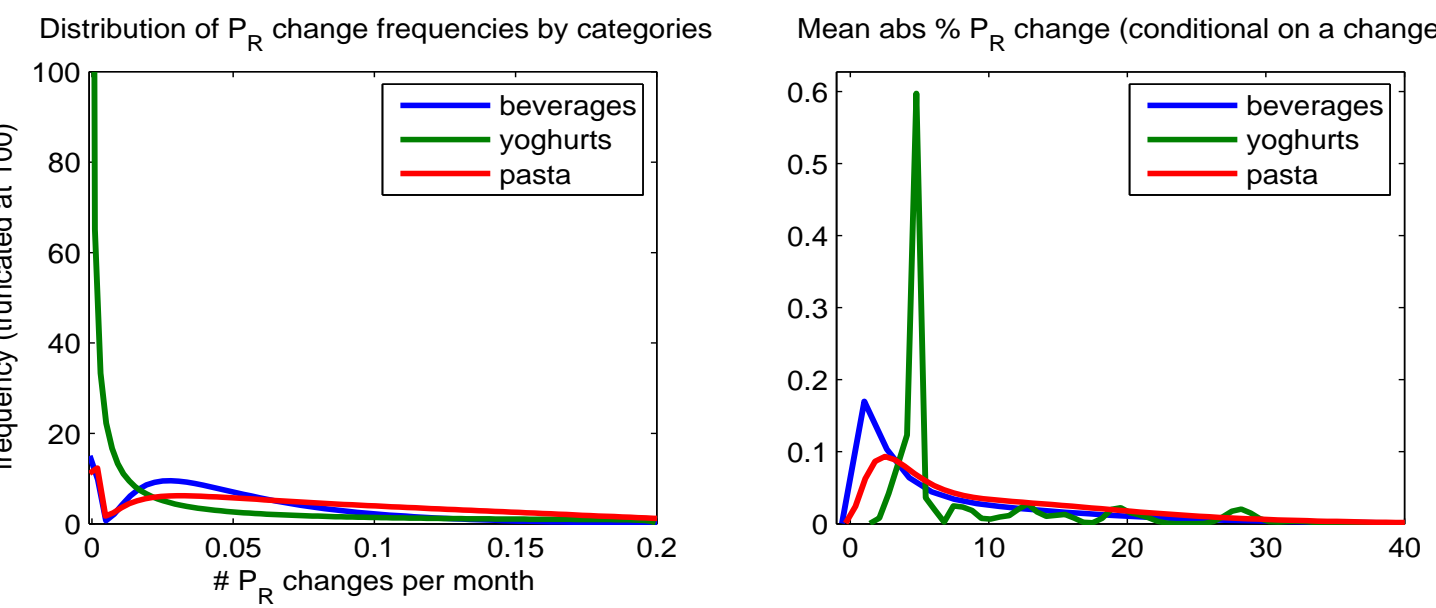

Frequency and size of $P_{R}$ changes (all goods)

Frequency and size of $P_{R}$ changes (beverages)
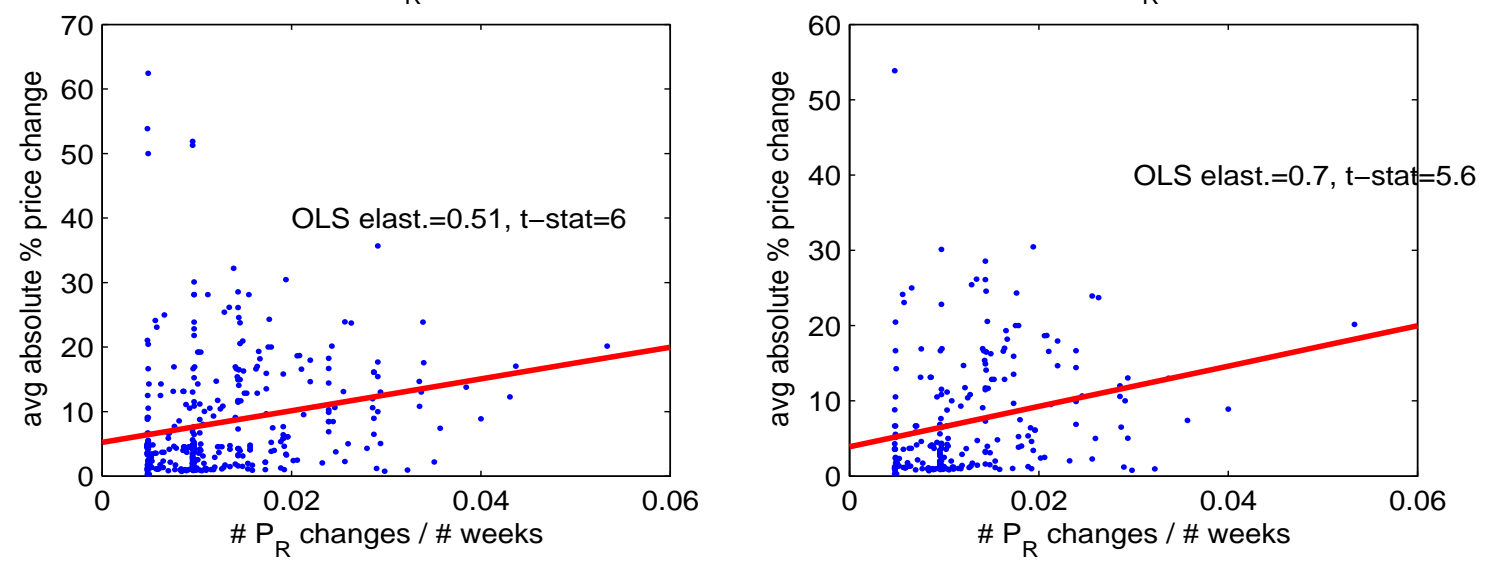

Frequency and size of $\mathrm{P}_{\mathrm{R}}$ changes (yoghurts)

Frequency and size of $P_{R}$ changes (pasta)
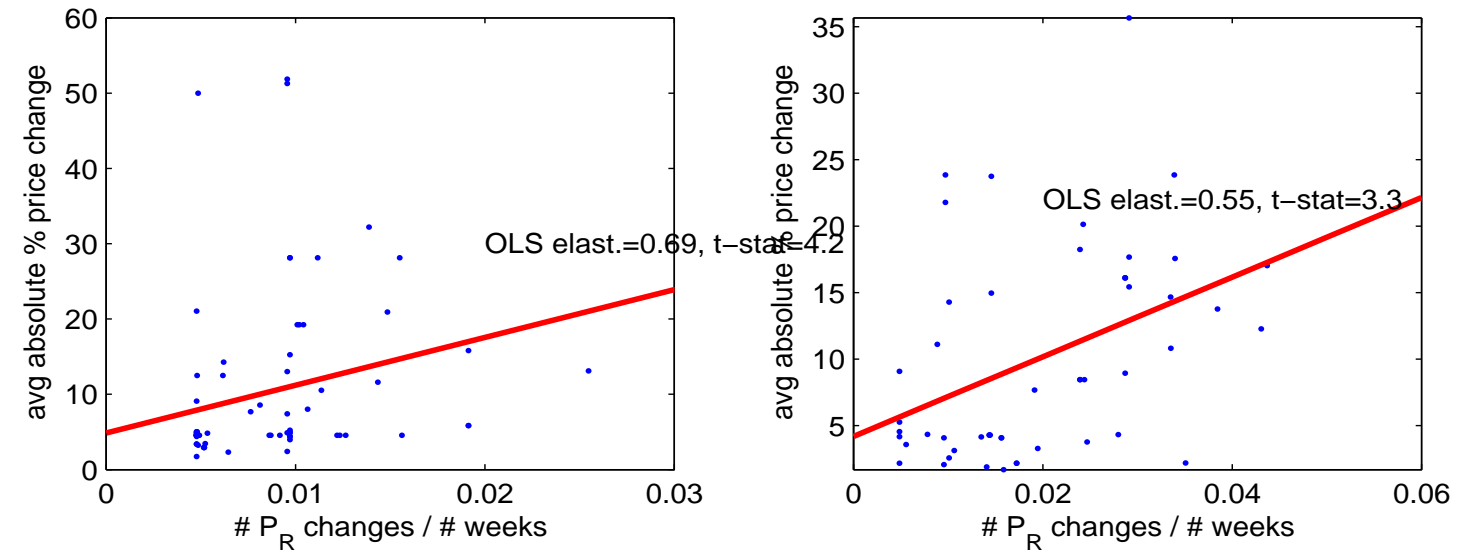
Figure 10: Response of quantities to price declines

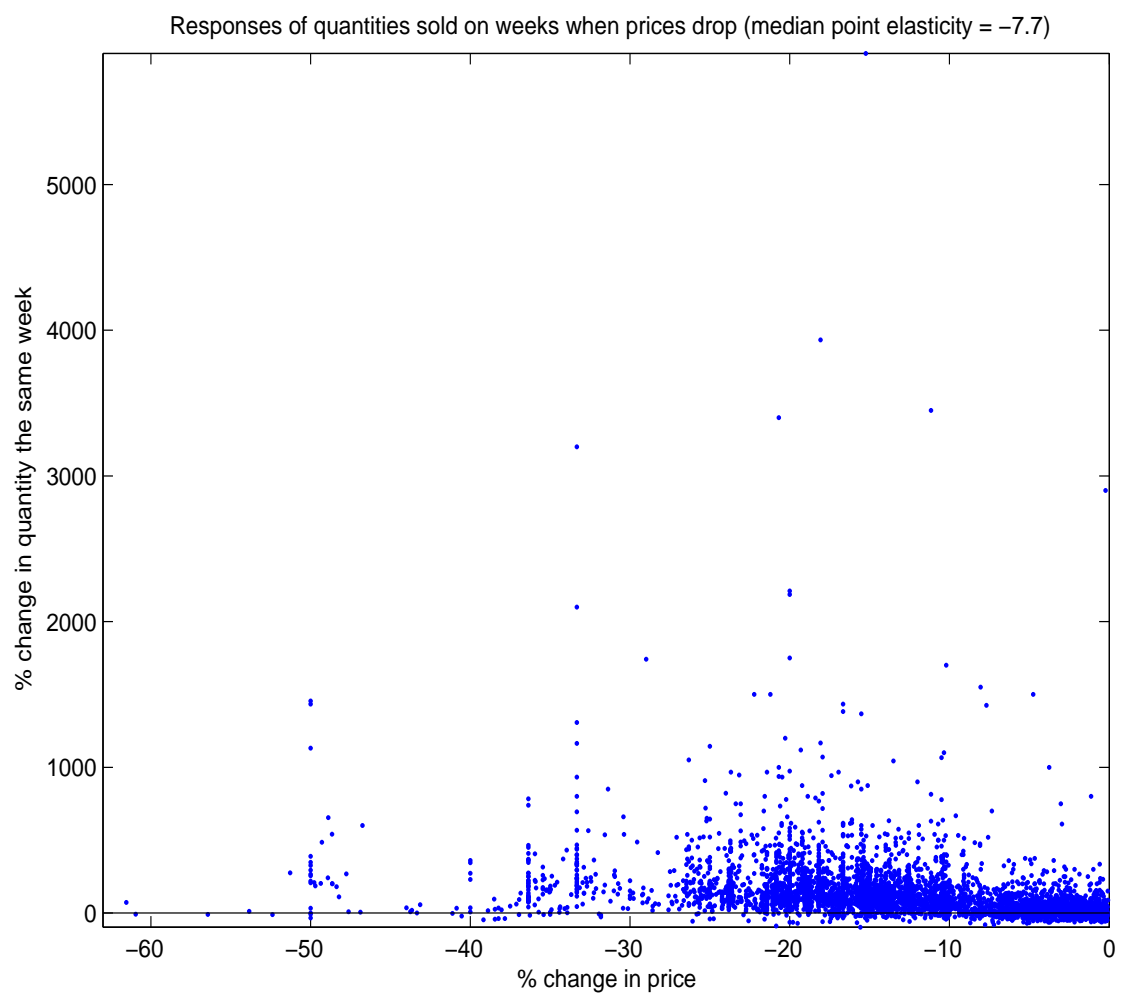


Figure 11: Effective prices

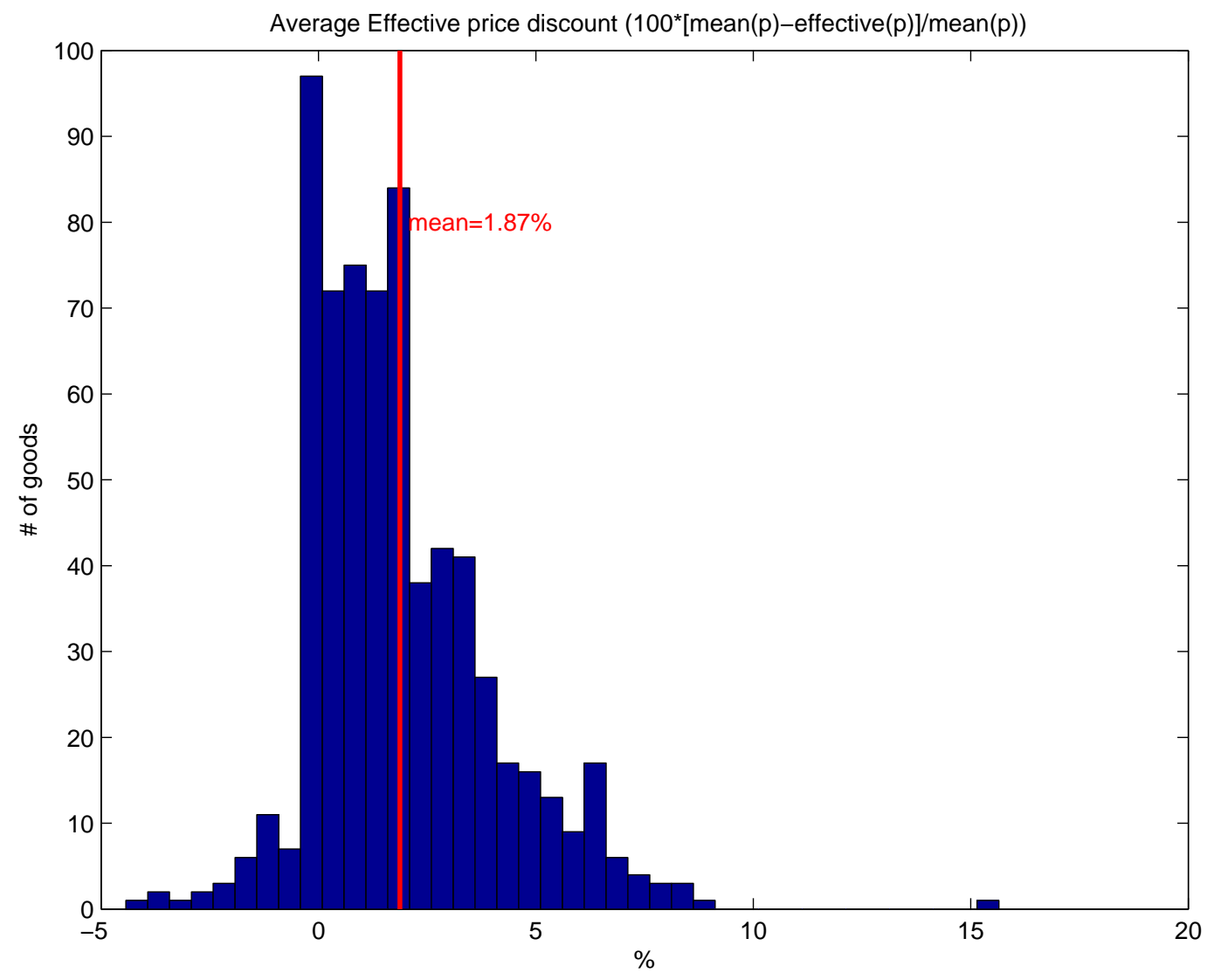


Figure 12: Synchronicity of sales within categories of substitutable products

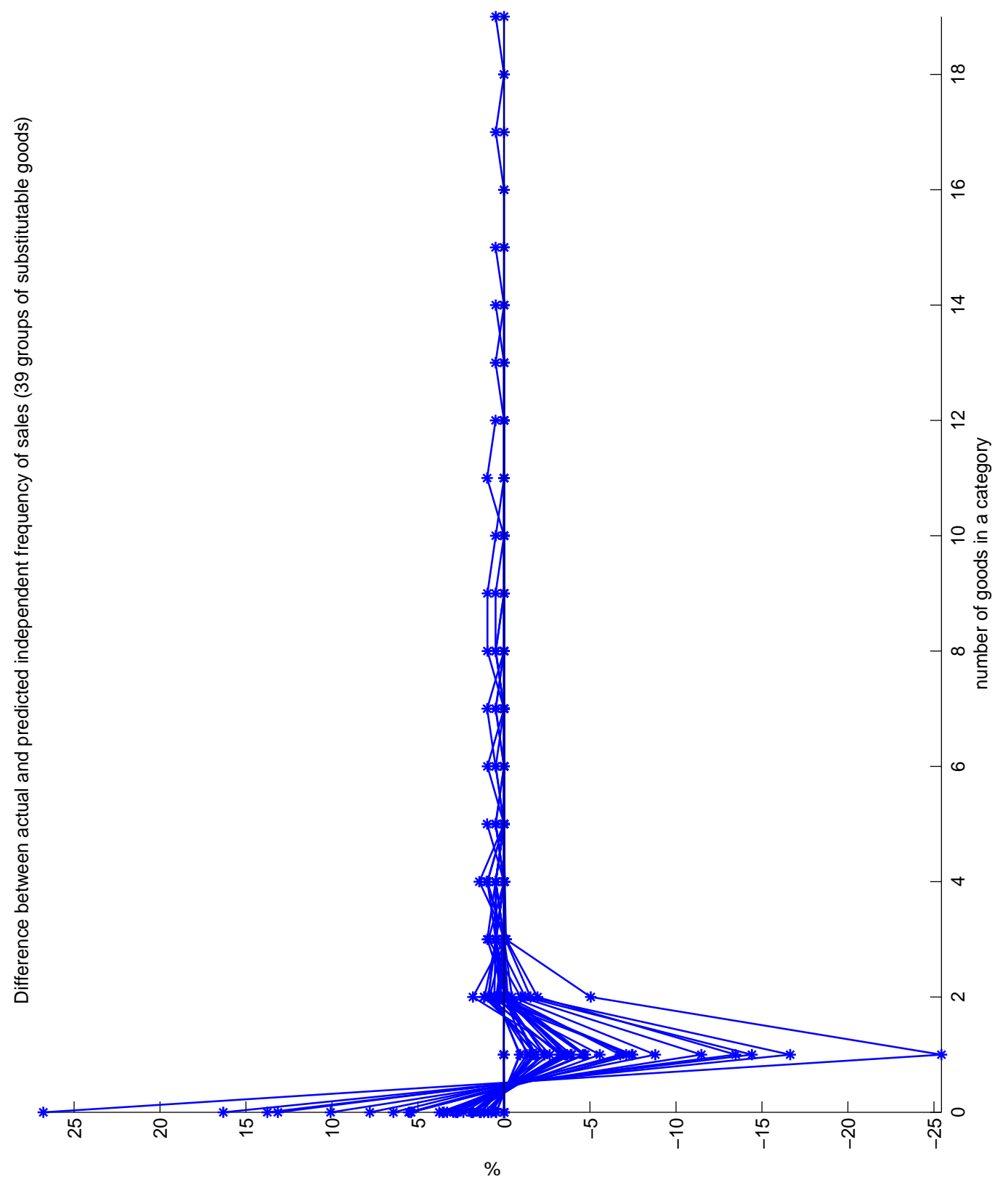

